\title{
Characterizing the Synoptic Expression of the Angola Low 0
}

\author{
EMMA HOWARD AND RICHARD WASHINGTON \\ School of Geography and the Environment, University of Oxford, Oxford, United Kingdom
}

(Manuscript received 11 January 2018, in final form 19 April 2018)

\begin{abstract}
The Angola low is a key feature of the southern Africa wet season atmosphere that influences precipitation across the continent. This paper uses ERA-Interim to show that the synoptic expression of the Angola low is a combination of dry heat lows and moist tropical low pressure systems. The Angola heat low and Angola tropical low composites are contrasted against similar lows observed in other continental tropical regions and found to be broadly comparable. The implications that the distinction between dry and moist events has for the interannual relationship among the Angola low, precipitation, and ENSO are examined. The tropical lows exhibit unusual semistationary behavior by lingering in the Angola region rather than traveling offshore. This behavior is proposed to be caused by an integrated sea breeze-anabatic wind that enhances (inhibits) cyclonic vorticity stretching and convection inland (near the coast). The combined effect of the heat lows and the anchored tropical lows creates the Angola low in the climatological average. By elucidating the mechanisms of the Angola low, this research improves the foundation of process-based evaluation of southern Africa present and future climate in CMIP and AMIP models.
\end{abstract}

\section{Introduction}

Precipitation underpins the lives of 150 million people in southern Africa. ${ }^{1}$ Shifts in rainfall can undercut agricultural production, undermine water, food, and energy security, and ultimately threaten the economic viability of the region (Conway et al. 2015). In this region, rainfall is strongly variable on a wide range of time scales, from intraseasonal to decadal (Reason et al. 2006). The local climate dynamics driving precipitation variability are complex, and a comprehensive understanding of the processes that force the local climate remains elusive. With approximately $60 \%$ of the region over $800 \mathrm{~m}$ above sea level (NOAA 1988) and spanning over $20^{\circ}$ of latitude from the tropics to the midlatitudes, southern Africa exists in the nexus of competing climatic features. One such feature, the Angola low, is known to have a central influence

\footnotetext{
${ }^{1}$ Loosely defined here as mainland Africa south of $10^{\circ} \mathrm{S}$.
}

Supplemental information related to this paper is available at the Journals Online website: https://doi.org/10.1175/JCLI-D-180017.s1.

Corresponding author: Emma Howard, emma.howard@ouce.ox. ac.uk over wet season precipitation across the subcontinent (e.g., Reason and Jagadheesha 2005; Cook et al. 2004).

The Angola low is a semipermanent low pressure system associated with cyclonic circulation. It is easily identifiable in the December-February climatology of near-surface geopotential height (e.g., Munday and Washington 2017) as shown in Fig. 1. The system is centered over eastern Angola at about $13^{\circ} \mathrm{S}$ and extends into surrounding countries. It is associated with the convergence of moisture flux originating from the western Indian and southeastern Atlantic Oceans, and thus modulates moisture transport into the subcontinent (Rouault et al. 2003).

The Angola low was first named as a distinct feature by Zunckel et al. (1996) although the first comprehensive analysis of its meteorology was developed by Mulenga (1998). Perhaps because of the dearth of circulation data over remote western Zambia and war-torn eastern Angola, the integrity of the closed Angola low circulation had remained elusive to pioneers of southern Africa climate who described the broad convergence zone in which the feature tends to develop as the Congo air boundary (Taljaard 1953, 1972) and also as the Zaire air boundary.

\section{a. Angola low significance}

The development of climate models and reanalysis products has shone light on the vital role of the Angola 


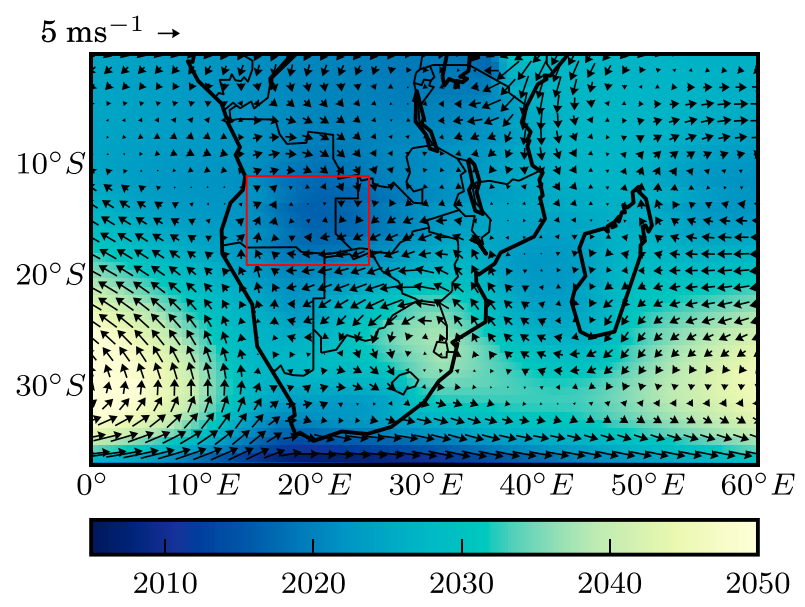

FIG. 1. Mean geopotential height ( $\mathrm{m}$; color-filled contours) and winds ( $\mathrm{m} \mathrm{s}^{-1}$; vectors) at $800 \mathrm{hPa}$ over southern Africa over the months of December, January, and February from 1979 to 2015. The Angola low is visible as a low pressure system featuring cyclonic circulation centered at $13^{\circ} \mathrm{S}, 20^{\circ} \mathrm{E}$. The red box indicates the primary region of interest for this study.

low in the dynamics of southern Africa climate. Cook et al. (2004) studied composites of wet and dry spells based on South African rain gauge data. They found that wet spells are associated with stronger Angola low circulations in NCEP-2 reanalysis data than dry spells. In addition to this, Munday and Washington (2017) have shown that in some regions of southern Africa, $40 \%-$ $60 \%$ of the intermodel precipitation variability between historical CMIP5 models can be explained by the simulated depth of the Angola low.

The dominant mode of interannual variability in southern Africa precipitation is El Niño-Southern Oscillation (ENSO) (e.g., Lindesay 1988). Through the El Niño phase, ENSO is a key driver of some of the most severe recent droughts in the region. Based on an examination of the circulation over southern Africa in a well-spread sample of three El Niño and two La Niña summers, Reason and Jagadheesha (2005) suggested that the Angola low has a modulating influence of ENSO on southern Africa precipitation.

There is also evidence that the Angola low may be a precursor to tropical-temperate trough (TTT) formation (Todd and Washington 1999; Hart et al. 2010), which provides a significant proportion of rainfall across the whole of the southern Africa region (Harrison 1984). The Angola low enables southward transport of atmospheric water vapor from the tropics, crucial to the development of TTTs. In an idealized model experiment, Cook (2000) found that an idealized thermal low similar to the Angola low acts as a root zone for a land-based convergence zone analogous to the South Indian convergence zone (SICZ), the time-mean manifestation of TTTs.
Future changes in the Angola low are likely to impact southern Africa precipitation. Vizy and Cook (2016) observe a recent strengthening of the Angola low in multiple reanalysis datasets from 1982 to 2013, by examining trends in mean sea level pressure and surface winds. They find that this is associated with sea surface temperature warming off the Angola coast in concert with a decrease in coastal upwelling in the eastern South Atlantic. Similarly, Vizy et al. (2015) studied a regional climate model representing projections of southern Africa climate into the late twenty-first century. In their simulations, a shortening of the wet season over Malawi was linked to a projected strengthening of the continental lows, including the Angola low, in April, associated with increased surface heating due to anthropogenic climate change.

Considering its importance to the regional climate, it is crucial that the mechanisms that drive the Angola low are well understood so as to increase confidence in future projections of southern Africa precipitation. However at present, the dynamics of the Angola low, particularly on a synoptic time scale, are not clear. Furthermore, a paucity of measurement data in tropical Africa means that process-based evaluation of climate models is often more feasible than performance-based evaluations (James et al. 2018). An understanding of the mechanisms of the Angola low will allow process-based evaluation of climate models to reduce the uncertainty around future projections of regional precipitation changes.

\section{b. Angola low dynamics}

Traditionally, the Angola low has been considered to be a dry thermal low, following the theoretical framework of Rácz and Smith (1999). The idealized work of Spengler et al. (2005) and Reason (1996) predicts that at tropical and subtropical latitudes, continental heat lows will form on the western sides of continents due to the interaction of the background easterly flow with the surface heating and topography. Many aspects of the Angola low are consistent with this framework. Mulenga (1998) found that the Angola low could be formed in a quasigeostrophic model of southern Africa as a Matsuno-Gill response to surface heating, using a similar method to Leslie (1980).

However, there is emerging evidence that moist convection may be as important to the Angola low as dry convection. Mulenga (1998) remarks that the Angola low may act as an anchor point for deep tropical convection. Further to this, Munday and Washington (2017) found that the convection driving the Angola low shifts from being shallow and dry to moist and deep at around midsummer each year. Particularly notable instances of 
deep convection in the Angola region have occurred when Indian Ocean tropical cyclones, including Eline in February 2000 (Reason and Keibel 2004) and Bonita in January 1996 (Mudenda and Mumba 1996), have crossed onto the African continent in Mozambique and traversed up the Zambezi River basin to merge with the Angola low.

\section{c. Paper aims and structure}

Despite its evident importance to southern Africa climate system on many time scales, the Angola low is typically considered as a feature of the seasonal mean. Little attention has been paid to its dynamics or synoptic expression. The focus of this paper is to perform a detailed analysis of the Angola low as modeled in the ERA-Interim database.

We diagnose the Angola low as a combination of early-season heat low events and late-season transient tropical low events, which we denote the Angola heat low and the Angola tropical low. We investigate the bearing this division has on the relationship between the Angola low and precipitation. Our findings indicate that the interannual variability of the tropical lows is correlated to interannual summer precipitation variability. In contrast, we find that the interannual variability of the heat lows has no bearing on precipitation variability. While heat low events fit nicely into the idealized theory described by Rácz and Smith (1999) and Spengler et al. (2005), the tropical lows are dynamically similar to transient monsoon lows and depressions that have been observed across India and northern Australia (Hunt et al. 2016). These southern African tropical lows, which form within the tropical rainband, are semistationary and linger in the Angola low region, in contrast to those that form elsewhere. We find evidence suggesting that this behavior may stem from the interactions of the west coast sea breeze with an anabatic wind associated with the steep escarpment along the Angola-Namibia coast. This integrated sea breeze-anabatic wind will be referred to as an anabatic sea breeze for brevity.

The remainder of this paper proceeds as follows. Section 3 classifies the Angola low as a series of thermal lows (the Angola heat low) and tropical lows (the Angola tropical low). We then examine the synoptic characteristics of each of the two phases. In section 4 we establish the influence of ENSO on the Angola low, and then examine the different effects of the Angola heat low and the Angola tropical low on precipitation. The paper then moves toward an understanding of the local drivers of the Angola low in section 5. The final section summarizes the research findings and discusses its implications.

\section{Data and methods}

This study uses the ERA-Interim dataset (ECMWF 2009) at native resolution $\left(0.75^{\circ}\right.$ in latitude/longitude), as described by Dee et al. (2011). A total of 37 austral summers were analyzed, starting in September 1979 and ending in March 2016. Data are analyzed on a daily time scale unless otherwise indicated. The primary region of interest is southern Angola and northern Namibia $\left(11^{\circ}-19^{\circ} \mathrm{S}, 14^{\circ}-25^{\circ} \mathrm{E}\right)$. This analysis was repeated using 3-hourly MERRA-2 data (NASA 2016), spanning from September 1980 to March 2016. The results of this analysis were qualitatively similar to those obtained from ERAInterim and led to the same conclusions. For brevity, only the ERA-Interim results are presented in this paper.

To identify Angola low events, we consider the daily mean vorticity within the region of interest described above. For each day in the sample period, grid cells with vorticity at $800 \mathrm{hPa}$ less than $-4 \times 10^{-5} \mathrm{~s}^{-1}$ were classified as Angola low grid cells, and classified as a heat low or tropical low. The choice of the vorticity threshold and the definition of classification system are described in section 3a. The center of an Angola low event at a point in that time is then calculated as the centroid of a group of adjacent Angola low grid cells of the same phase. This method allows for multiple events to exist in the region of interest at a period of time, provided that none of their constituent grid cells are adjacent. The average number of grid cells that were identified in each cluster was 6.2 , implying a radius of about $100 \mathrm{~km}$. Each cluster represents the core of a cyclonic system, and so the total radius of the cluster is often larger than this core. Of these clusters, $90 \%$ contained fewer than 15 grid cells. However, the distribution of the cluster sizes was highly skewed, and the largest cluster identified contained 57 grid cells. This cluster occurred on 18 January 1996, when Mudenda and Mumba (1996) report that the former Tropical Cyclone Bonita had merged with the Angola low. The sensitivity of all results to the relative vorticity threshold has been tested using a threshold of $-3.5 \times 10^{-5} \mathrm{~s}^{-1}$. This increased the number of Angola low grid cells flagged, but all other results were qualitatively unchanged and the statistical significance of the results still held in all cases.

We have used composite analysis to study the structure of various atmospheric fields during Angola low events. To remove the effect of the seasonal cycle, a 14-day running mean climatology is subtracted from both the composite sample and the population before testing. A two-tailed Welch's $t$ test is then applied to test the null hypothesis that the composite mean anomaly is the same as that of the climatology. Autocorrelation within the composite samples has been controlled for by assuming 
that the data follow a first-order autoregressive process and calculating an effective sample size using the lag-1 autocorrelation coefficient. The false discovery rate (FDR) is controlled by calculating a threshold level $p_{\mathrm{FDR}}^{*}$ based on an FDR control value of $\alpha_{\mathrm{FDR}}=0.05$ (Wilks 2011). A combined value of $p_{\mathrm{FDR}}^{*}$ is calculated for each multipanel figure and is presented in each figure caption. Despite the use of anomalies to calculate significance, we have elected to show the full fields in the composite plots. We found this displayed greater clarity of the overall results.

\section{Synoptic characteristics}

To study the synoptic events that comprise the Angola low, we generated a set of time and space coordinates in the study area that featured strong cyclonic relative vorticity. We then studied the phase space of various atmospheric variables at the identified coordinates. This revealed two clear clusters of synoptic events. In this section, we describe the method used to classify the two clusters, the synoptic characteristics of the two clusters of low pressure systems, and finally the behavior of the systems. Despite the low latitude of the study area, we find that geostrophic balance is still a useful approximation. Above the boundary layer, the overall magnitude of the ageostrophic component is about $33 \%$ of the overall magnitude of the geostrophic component.

\section{a. Classification system}

The distinction between the Angola heat low and the Angola tropical low on the daily time scale has been characterized by considering the dry static stability of events with strong cyclonic vorticity. For each day in the study period, grid cells in the primary region of interest $\left(11^{\circ}-19^{\circ} \mathrm{S}, 14^{\circ}-25^{\circ} \mathrm{E}\right)$ with daily mean relative vorticity at $800 \mathrm{hPa}$ less than $-4 \times 10^{-5} \mathrm{~s}^{-1}$ have been identified. A heat map of the static stability at $700 \mathrm{hPa}$ against the $800-\mathrm{hPa}$ relative vorticity is given in Fig. 2. From Fig. 2 it can be seen that there are two distinct clusters of events, those with high static stability (above $0.0033 \mathrm{~K} \mathrm{~m}^{-1}$; blue) and those with low static stability (below $0.0033 \mathrm{~K} \mathrm{~m}^{-1}$; red). Figure 2, bottom, shows a parameter-space heat map of specific humidity against static stability. This demonstrates that the clustering is also present in specific humidity, with the more (less) statically stable events being wetter (drier). Here, the static stability is taken as the vertical derivative of potential temperature. Other parameters (not shown) including temperature and potential vorticity also show this clear distinction between the two types of events. The vorticity threshold was chosen as the weakest threshold at which a bimodal distribution emerged in Fig. 2 with
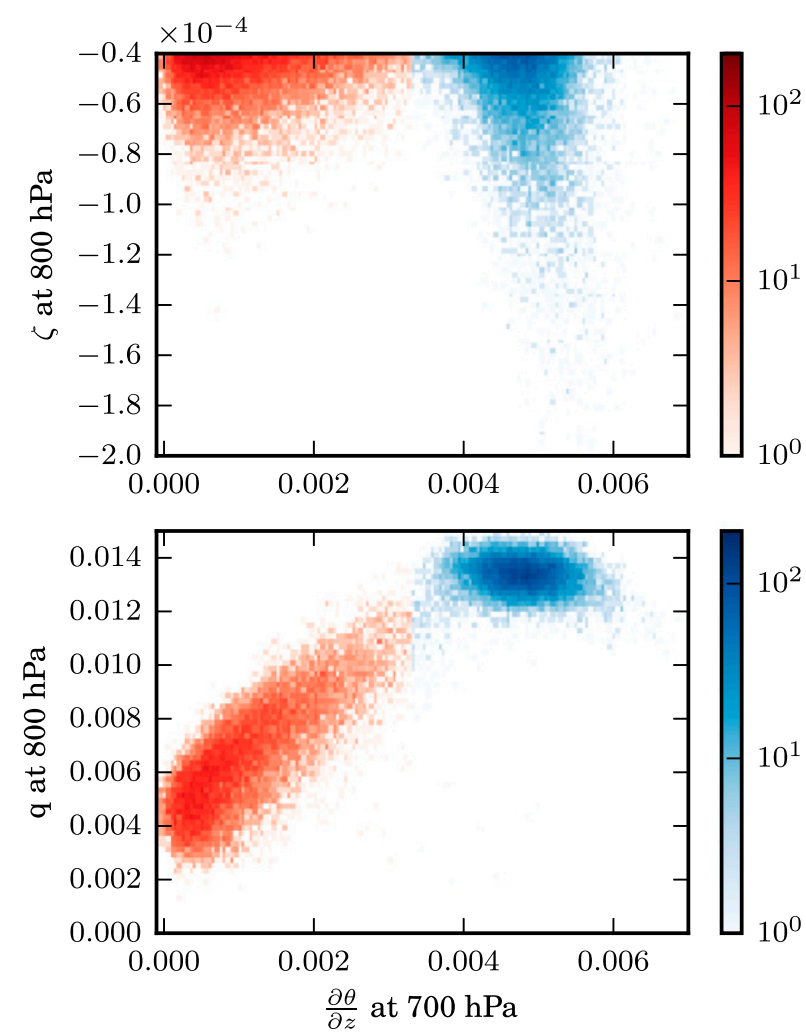

FIG. 2. Log-scaled phase-space heat maps of relative vorticity, stability, and humidity in the Angola low region on days featuring cyclonic relative vorticity exceeding $4 \times 10^{-5} \mathrm{~s}^{-1}$. (top) The 800 -hPa relative vorticity $\left(\mathrm{s}^{-1}\right)$ against $700-\mathrm{hPa}$ stability $\left(\mathrm{K} \mathrm{m}^{-1}\right)$ and (bottom) $800-\mathrm{hPa}$ specific humidity $\left(\mathrm{kg} \mathrm{kg}^{-1}\right)$ against $700-\mathrm{hPa}$ stability $\left(\mathrm{K} \mathrm{m}^{-1}\right)$. Blue areas show tropical low grid cells, while red areas show heat low grid cells.

minimal overlap between the clusters. As noted earlier, lowering the vorticity threshold to $-3.5 \times 10^{-5} \mathrm{~s}^{-1}$ does not change the results significantly; however, we choose to use the stronger threshold to keep the clusters more distinct. Based on the results of Fig. 2, each vertical profile in the region of interest and study period with $800-\mathrm{hPa}$ relative vorticity less than $-4 \times 10^{-5} \mathrm{~s}^{-1}$ is classified as a heat low (tropical low) grid cell if its static stability at $700 \mathrm{hPa}$ is less than (greater than) $0.0033 \mathrm{~K} \mathrm{~m}^{-1}$.

The key differences between the dynamics and thermodynamics of the two phases of the Angola low are illustrated in Fig. 3. Figure 3 has been constructed by compositing vertical profiles of various atmospheric variables at the closest grid cell to the centroid of each heat low and tropical low event. It is evident that the heat lows are associated with cyclonic circulation capped at $700 \mathrm{hPa}$, hot surface temperatures, low surface humidity, and neutrally stratified static stability. This indicates that the heat lows in the Angola region feature shallow dry convection, as per the idealized heat lows studied by Rácz and Smith (1999). Conversely, the 

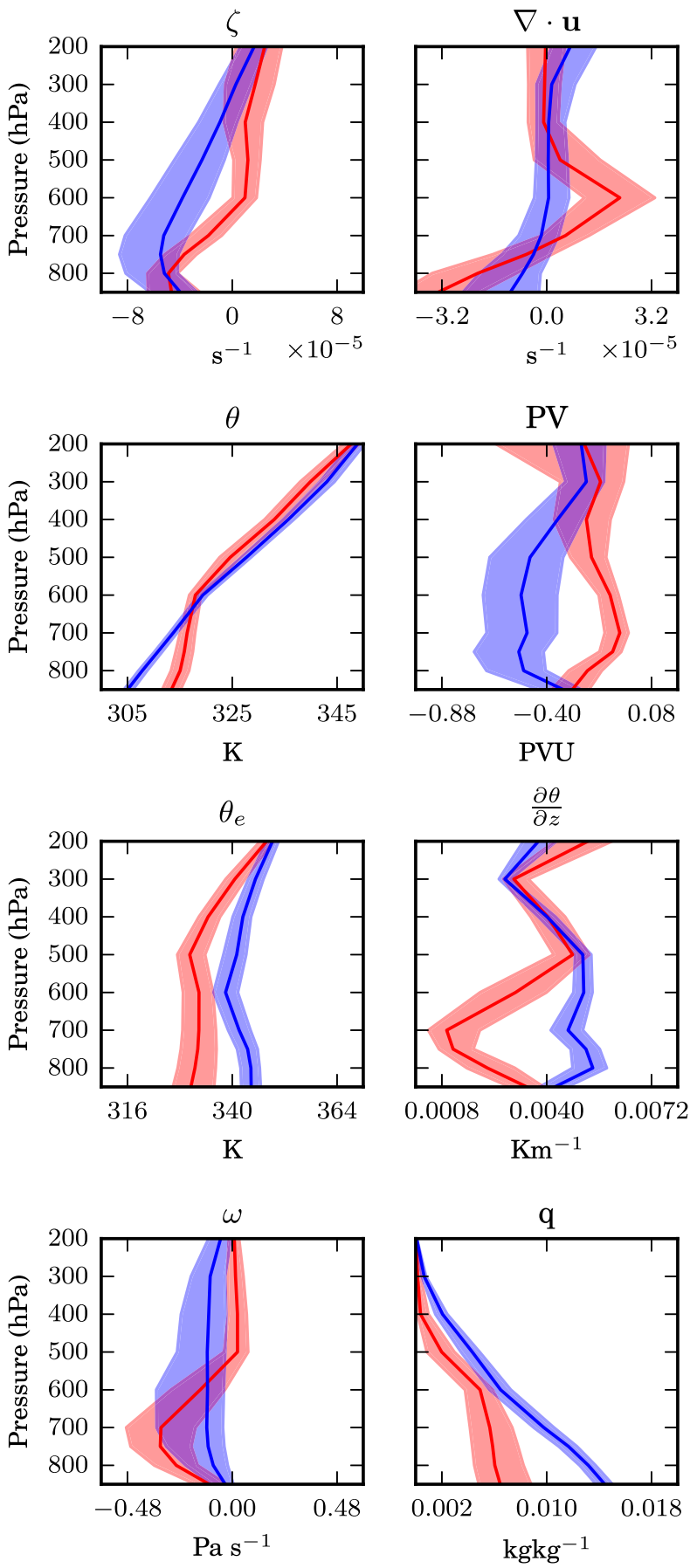

FIG. 3. Vertical profiles of (top left) relative vorticity, (top right) divergence, (second row, left) potential temperature, (second row, right) $\mathrm{PV}$, (third row, left) $\theta_{e}$, (third row, right) potential temperature lapse rate, (bottom left) vertical velocity, and (bottom right) specific humidity during Angola low events. Heat low profiles are shown in red and tropical low profiles are blue. Solid lines indicate the median value of the distributions, while the color-shaded bands represent one standard deviation either side of the median. tropical lows are associated with cyclonic circulation up to $300-400 \mathrm{hPa}$ and high surface humidity. While the dry static stability profile is stable, the moist stability, indicated by the equivalent potential temperature $\theta_{e}$ profile, is unstable. Thus the tropical lows feature deep moist convection, maintained by latent heat release.

Consistent with the finding of Munday and Washington (2017), a seasonal distinction between occurrences of the Angola heat low and the Angola tropical low is apparent. Figure 4 shows a 2D histogram map of where intense cyclonic circulation associated with dry and moist convection occur from October to March. The method used to identify heat low and tropical low grid cells is as described above; however, the results are shown for southern Africa. Dry convection is strongly evident in Angola from October to November, and moist convection is present from December to March. Also apparent is the moist convecting Mozambique Channel trough and the dry convecting Kalahari heat low, which are not the focus of this research. It is clear that the Angola low presents as the Angola heat low from October to November, and then transitions to the Angola tropical low during December when the wet season begins, and remains as the Angola tropical low until March. This leads us to investigate the synoptic structure of these two phases separately below.

\section{b. Angola heat low dynamics}

Key diurnal characteristics of the Angola heat low for comparison to the literature surrounding idealized heat lows are presented in Fig. 5. Figure 5 shows diurnal vertical west-east cross sections of winds and potential temperature during heat lows identified using the methodology described in section $3 \mathrm{a}$, centered on the centroid of the heat low grid cells. These cross sections are consistent with Figs. 6-9 of Rácz and Smith (1999) and Fig. 3 of Spengler and Smith (2008), which demonstrate vertical cross sections of potential temperature and winds in idealized heat low experiments. The authors found that the radial wind inflow is strongest overnight and rotates into a geostrophic tangential wind in the early morning, and that the potential temperature at the center of the heat lows is unstable in the middle of the day. A midlevel anticyclone sits above the heat low and is strongest in the morning.

The main difference between the idealized models and our ERA-Interim-based analysis is that the instability is weaker in the reanalysis. The weak instability may result from the averaging of many heat lows in our composite. The westerly zonal inflow resembles a sea breeze, which will be further discussed in section 5 . We also find that the upper-level jet that caps the upperlevel anticyclone is significantly stronger during the heat 

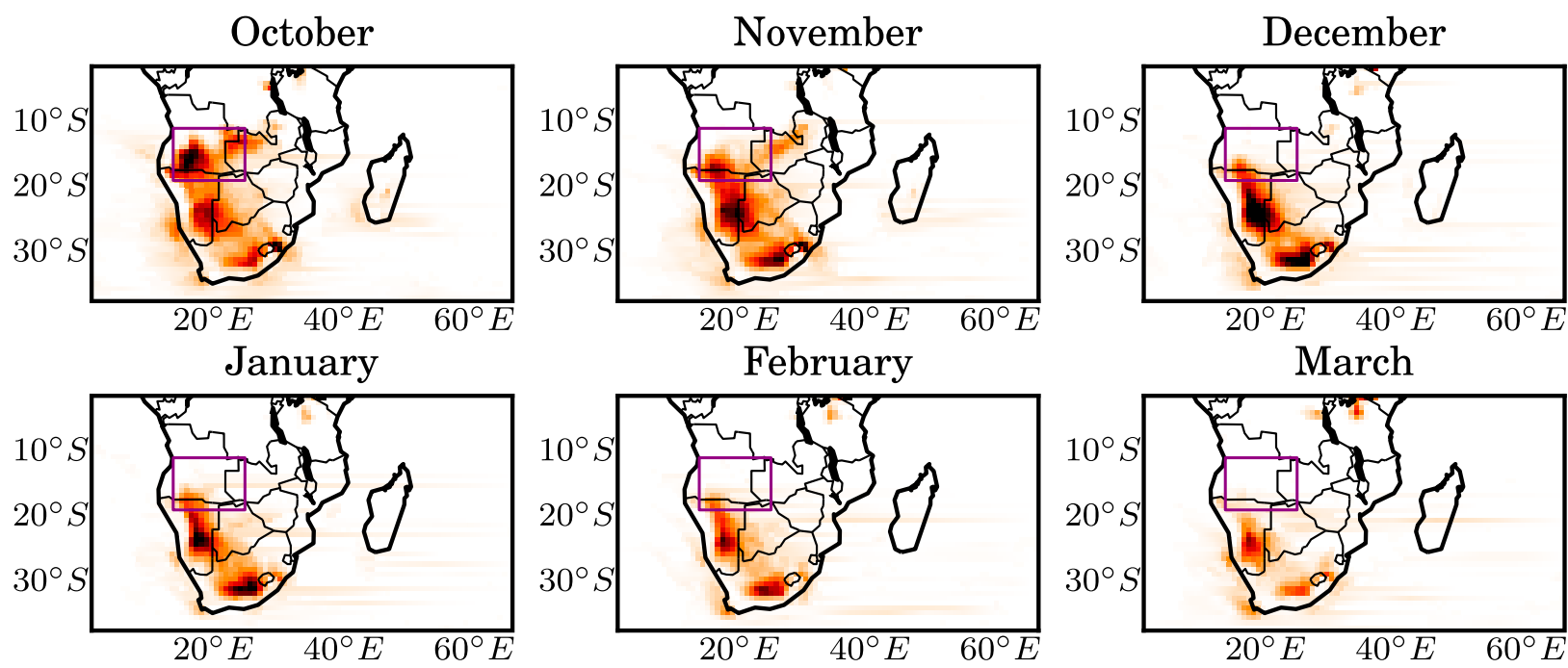

\section{October}
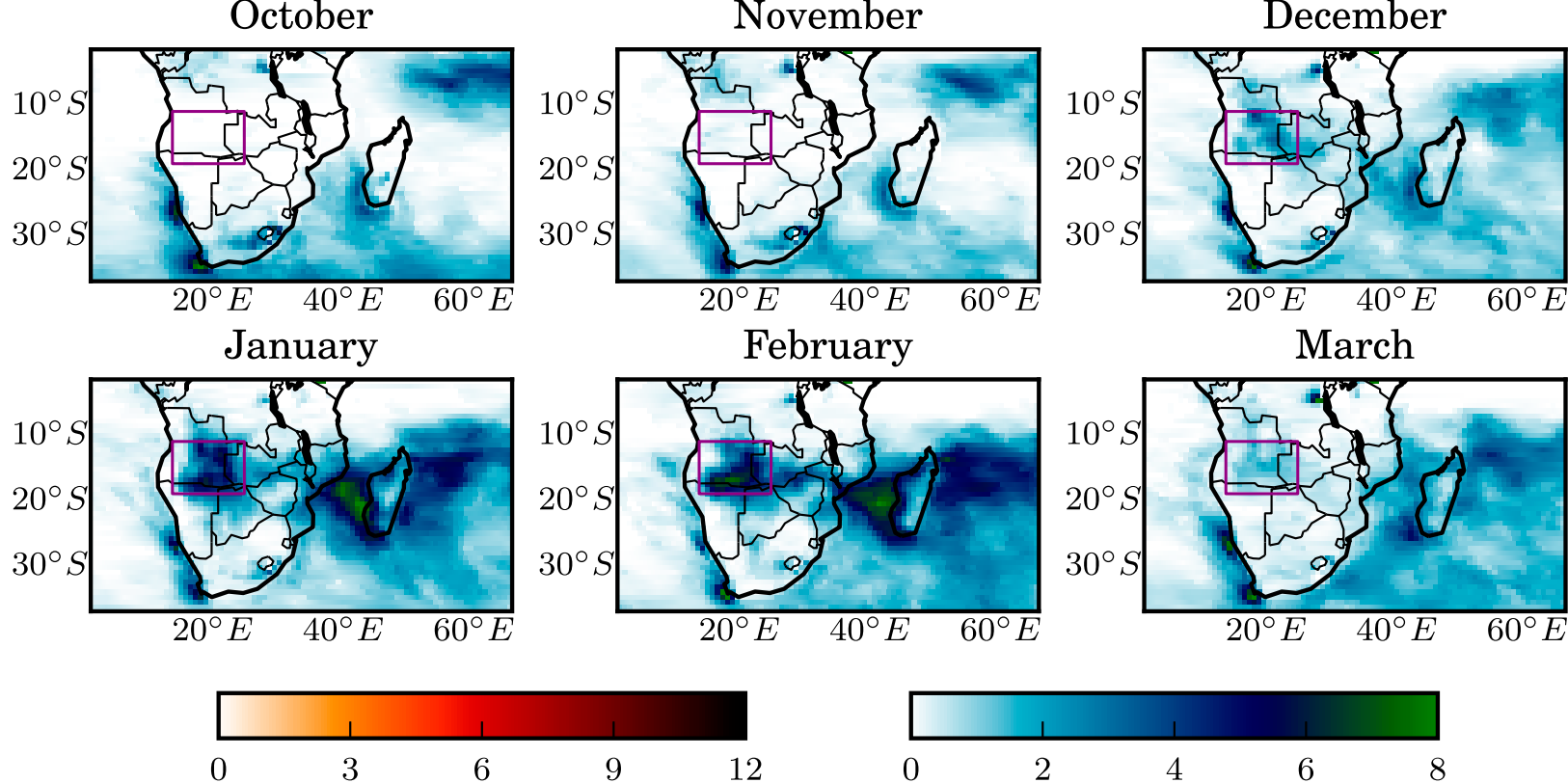

February
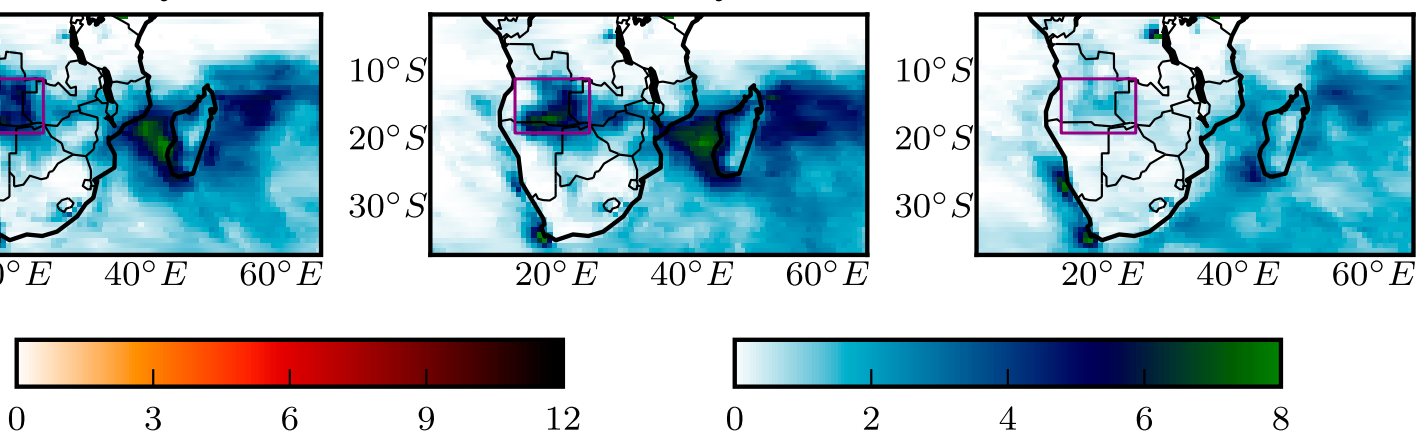

FIG. 4. Monthly heat map histograms of the locations where cyclonic circulations $\left(\zeta<-4 \times 10^{-5} \mathrm{~s}^{-1}\right)$ with neutral and unstable dry static stability have been identified in each month. Shown are monthly occurrences of (top rows) neutrally stratified cyclones with $\partial \theta / \partial z<$ $0.0033 \mathrm{~K} \mathrm{~m}^{-1}$ at $700 \mathrm{hPa}$ and (bottom rows) stably stratified cyclones with $\partial \theta / \partial z>0.0033 \mathrm{~K} \mathrm{~m}^{-1}$ at $700 \mathrm{hPa}$. The color scale represents the average number of events occurring at each grid point in a given year.

low than in the climatology, despite the fact that the climatological seasonal cycle was removed when statistical significance was calculated. Overall there is satisfactory evidence that the Angola heat low is indeed a thermal low in the traditional sense.

\section{c. Angola tropical low dynamics}

As cold-cored synoptic-scale lows that track over a tropical landmass, the tropical lows in the Angola region bear a resemblance to tropical low pressure systems, including monsoon depressions. Monsoon depressions have been most intensively studied over the Indian subcontinent (e.g., Hunt et al. 2016; Godbole 1977) but have also been studied over northern Australia (Berry et al. 2012). Hurley and Boos (2015) conducted a comprehensive study of these features across low-latitude landmasses and noted their similarities and differences across different regions of the globe, including southern Africa.

The Angola tropical low consists of a deep column of potential vorticity, extending from the surface to about $300 \mathrm{hPa}$ (Fig. 6). The panels in Fig. 6 show daily vertical west-east cross sections of various atmospheric variables during tropical lows identified using the 

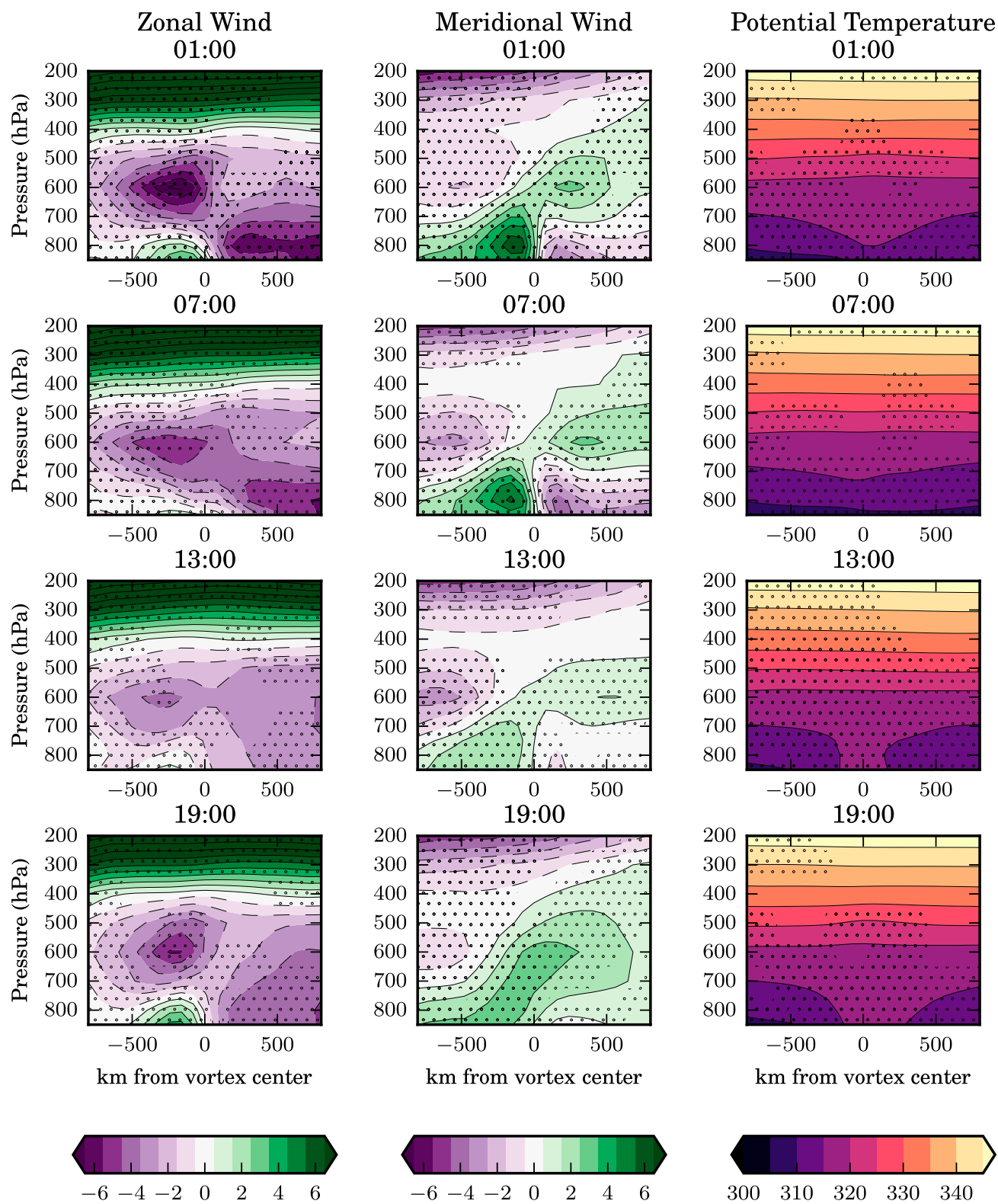

FIG. 5. Composite west-east cross sections with height of (left) zonal and (center) meridional wind $\left(\mathrm{m} \mathrm{s}^{-1}\right.$ ) and (right) potential temperature $(\mathrm{K})$ for heat low events (see text for definitions) at (top)-(bottom) 0100 , 0700, 1300, and 1900 LT. Stippling shows the statistically significant points using a threshold of $p_{\mathrm{FDR}}^{*}=0.037$.

methodology described in section $3 \mathrm{a}$, centered on the centroid of the tropical low grid cells. The temperature anomaly field features a dipole that is cool near the surface and warm in the upper troposphere. In contrast with the Angola heat low, the upper-level zonal winds during the Angola tropical low are easterly, suggesting that the tropical lows are embedded in the tropical easterly jet. The cyclonic circulation anomalies reach out from the center of the system approximately $500 \mathrm{~km}$, giving the total system an average diameter of $1000 \mathrm{~km}$. These observations are consistent with the structures of the Indian and northern Australian monsoon lows and depressions observed by Hunt et al. (2016), Berry et al. (2011), and Hurley and Boos (2015). This implies that the growth and propagation mechanisms of these circulations may resemble those of the tropical lows in Angola.

The implication that some low pressure systems over southern Africa are dynamically similar to monsoon depressions in Australia and India is not immediately reconcilable with the work of Hurley and Boos (2015). The southern Africa composites of 

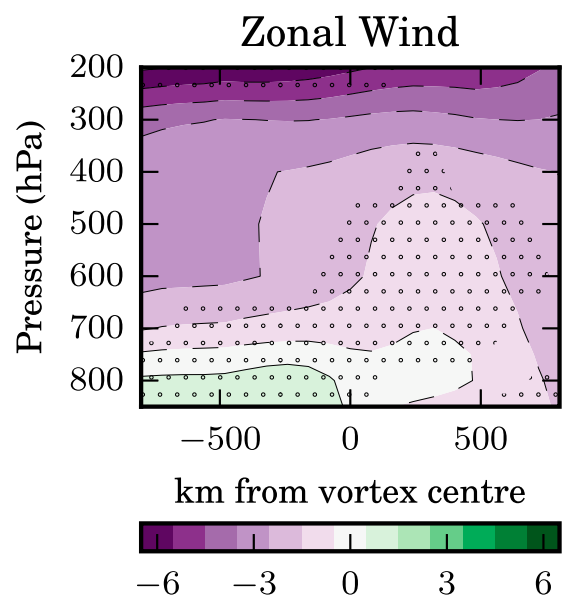
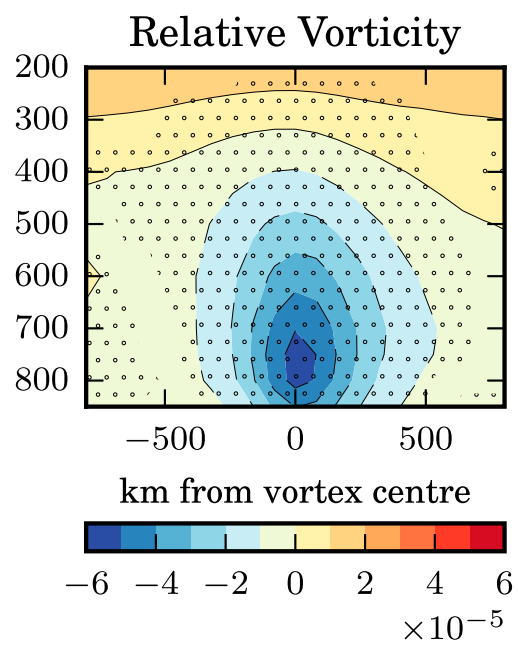

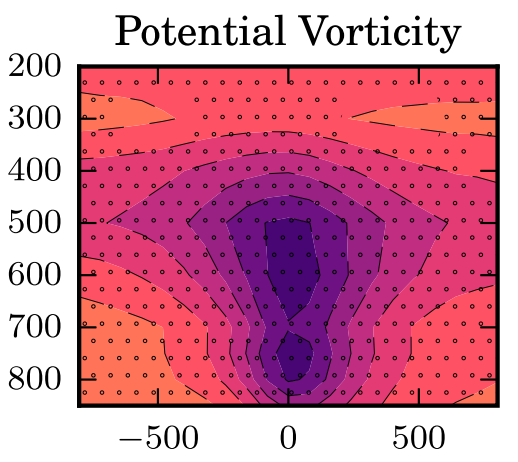

$\mathrm{km}$ from vortex centre

$\begin{array}{llll}-0.6 & -0.4 & -0.2 & 0.0\end{array}$

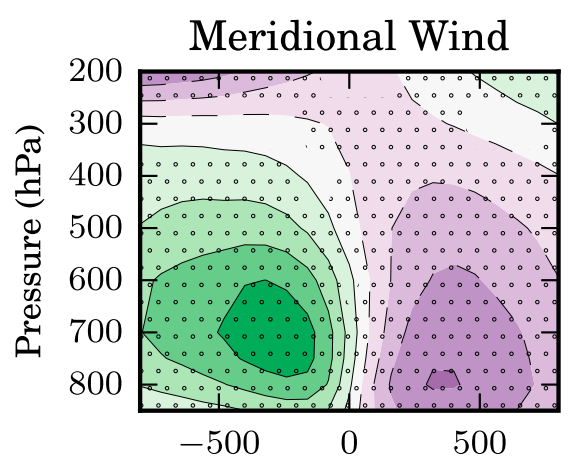

$\mathrm{km}$ from vortex centre

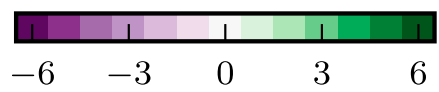

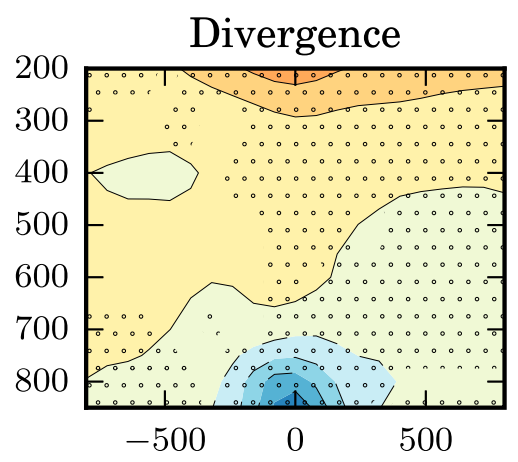

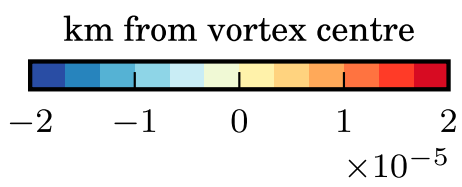

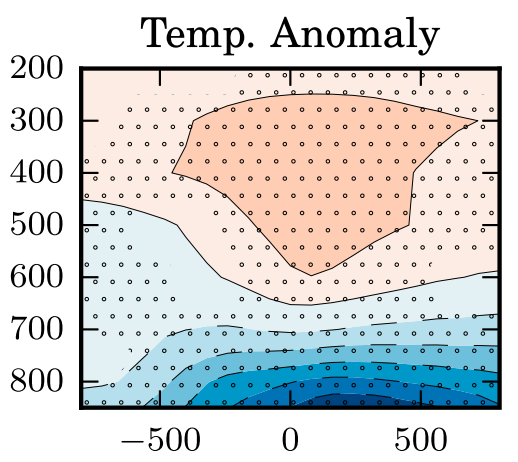

$\mathrm{km}$ from vortex centre

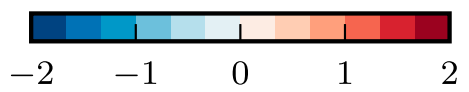

FIG. 6. Composite vertical west-east cross sections with height of (top left) zonal and (bottom right) meridional wind ( $\mathrm{m} \mathrm{s}^{-1}$ ), (top center) relative vorticity $\left(\mathrm{s}^{-1}\right)$, (bottom center) divergence $\left(\mathrm{s}^{-1}\right)$, (top right) PV (PVU), and (bottom right) temperature anomaly (K) for tropical low events (see text for definitions). Stippling shows the statistically significant points using a threshold $p_{\mathrm{FDR}}^{*}=0.040$.

Hurley and Boos (2015) do not show the characteristic temperature or PV structure of a typical monsoon low. However, their composite sample contains data from December to February and is performed over an area that extends down to $25^{\circ} \mathrm{S}$. Hence the sample will contain Kalahari and Angola heat lows as well as tropical lows, which would be expected to obscure the signal of the tropical depressions. Therefore we conclude that the tropical lows in the Angola region are dynamically related to the monsoon lows that have been observed over Australia and India. Hurley and Boos (2015) identified on average 12.5 low pressure systems from November to February in southern Africa, in contrast to 25 over the same period in Australia and 18 from May to August in India. Even before accounting for the fact that some of these systems may be heat lows, tropical lows are less common in southern Africa than in these other regions.

\section{d. Movement of synoptic events}

Figure 7 shows the longitudes and timing of grid cells in seven selected years that meet the threshold criteria of heat low and tropical low events. The years displayed in Fig. 7 have been chosen to represent a range of ENSO phases. In this instance, the domain has been extended to $11^{\circ}-19^{\circ} \mathrm{S}, 0^{\circ}-55^{\circ} \mathrm{E}$ and the classification has been run over 6-hourly data. Heat lows, shown in red, develop in two longitudinal bands centered on $18^{\circ}$ and $22^{\circ} \mathrm{E}$, which sometimes merge and rarely move more than $5^{\circ}$ longitude. The heat lows appear to be geographically locked and form only over the Angola region. By contrast tropical lows, shown in blue, travel east and west across the 

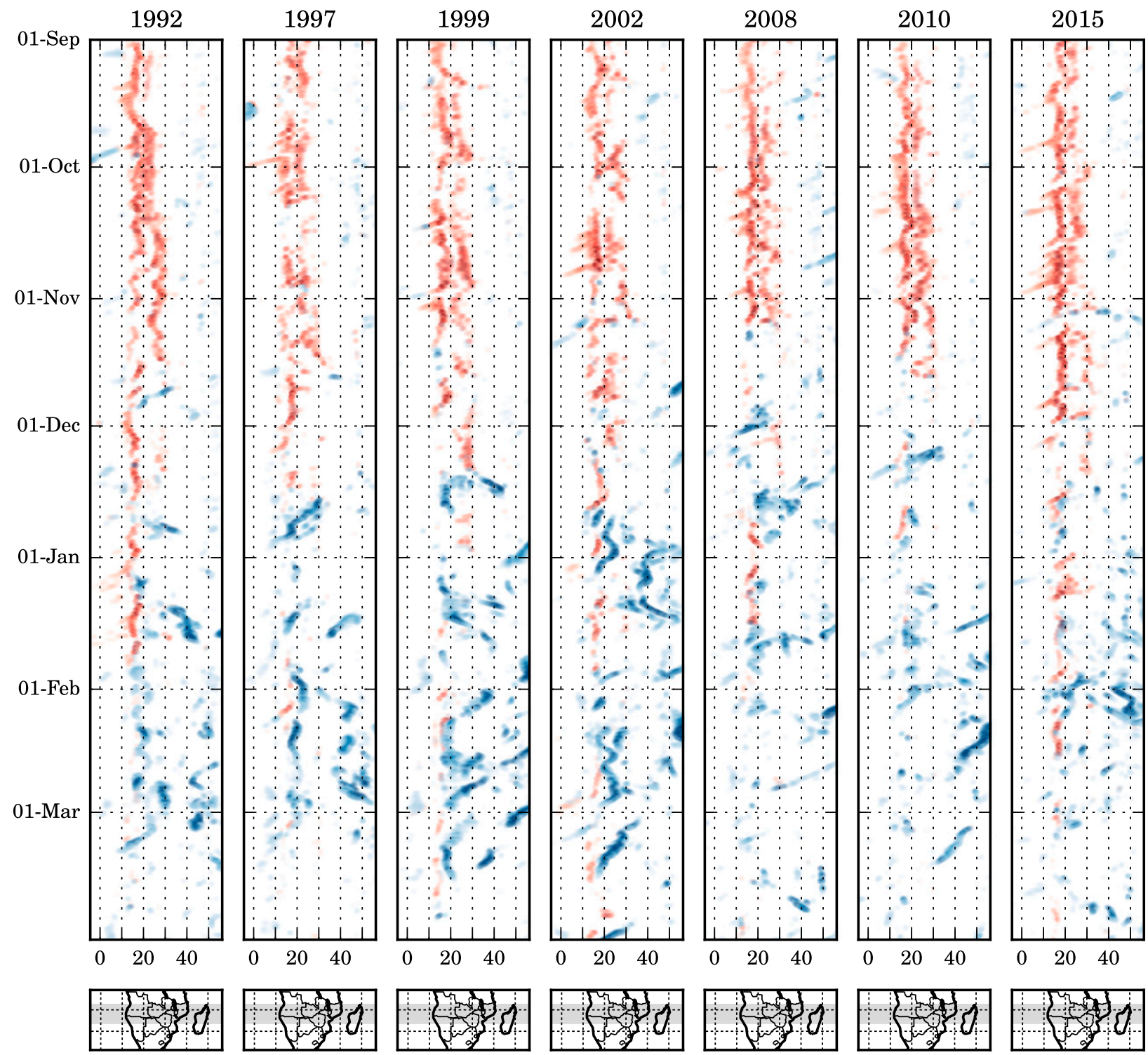

FIG. 7. (top) Longitude-time plots of the locations where cyclonic circulations $\left(\zeta<-4 \times 10^{-5} \mathrm{~s}^{-1}\right)$ have been identified in selected years between $11^{\circ}$ and $18^{\circ} \mathrm{S}$. Red dots denote neutrally stratified with $\partial \theta / \partial z<0.0033 \mathrm{~K} \mathrm{~m}^{-1}$ at $700 \mathrm{hPa}$, and blue dots denote stably stratified with $\partial \theta / \partial z>0.0033 \mathrm{~K} \mathrm{~m}^{-1}$ at $700 \mathrm{hPa}$. Color intensity represents cyclonic vorticity. Years shown are (left)-(right) 1992/93, 1997/98, 1999/00, 2002/03, 2008/09, 2010/11, and 2015/16. (bottom) Maps of southern Africa with the domain from the top panels shaded in gray and are provided for context.

African continent. However, these circulation features linger in the region of interest, appearing to become anchored at around $20^{\circ} \mathrm{E}$. This is at odds with tropical low pressure systems observed in Australia and India, which are predominantly transient systems (Hunt et al. 2016; Berry et al. 2011; Hurley and Boos 2015). Although a small number of tropical lows form in the Atlantic Ocean, they only rarely cross either east or west across the West African coast. This behavior is reflected across the all the years in the study period from 1979 to 2015 (not shown).
In the dry El Niño summer of 2015/16, the Angola heat low lasted well into February (Fig. 7). Meanwhile, the moist circulation features rarely reached the Angola region at all. By contrast, the wet El Niño summer of 1997/98 featured numerous semistationary tropical lows in the Angola low region. The extremely wet La Niña summer of 1999/2000 featured a large number of tropical low events tracking across the African continent from December onward, many of which lingered in the Angola region. Of particular note is the former Tropical Cyclone Eline, which penetrated mainland Africa in late February after 
crossing the Indian Ocean and reached $20^{\circ} \mathrm{S}$ (Reason and Keibel 2004). However, in the drier La Niña summer of 2010/11, although tropical low events were identified over southern Africa, none persisted in Angola for over a week. Inspired by these qualitative observations, the next section aims to clarify the interannual relationship between the phases of the Angola low, ENSO, and precipitation.

\section{Bearing on precipitation}

On an interannual time scale, the Angola low is believed to have an important connection to regional precipitation across southern Africa (Mulenga 1998). This may have a modulating impact on the relationship between southern Africa precipitation and ENSO. The El Niño phase of ENSO is typically associated with drought in southern Africa, a result of the shift in the Walker circulation. The 1982/83 and 2015/16 El Niño events both occurred in years where the Angola low was weak, and resulted in severe drought. The 1997/98 El Niño, however, coincided with a strong Angola low and a drought was not observed. ${ }^{2}$ The differences between these El Niño summers have been well studied. Reason and Jagadheesha (2005) found that the interannual variability of the Angola low modulates the rainfall impacts of ENSO. Lyon and Mason (2007) confirmed the role of the Angola low and also found that high sea surface temperatures near southern Africa and anomalous shifts in Walker circulation all contributed to the increase in precipitation in $1997 / 98$ as compared to 1982/83.

The separation of the Angola low into the Angola heat low and the Angola tropical low adds clarity to its relationship with ENSO and precipitation. An Angola heat low index (AHLI) and an Angola tropical low index (ATLI) have been created by counting the number of days per year when each class of Angola low has been identified from November to March, and normalizing such that the maximum value of the index is 1 . The normalized sum of the AHLI and the ATLI is referred to as the Angola low index (ALI). It may be expected that the indices are anticorrelated, since both indices will be dependent on the date of the transition from the Angola heat low to the Angola tropical low. If the transition is earlier (later) than normal, then there will

\footnotetext{
${ }^{2}$ These three summers featured the strongest El Niño events of the study period, with average Niño-3.4 SST indices from November to March respectively 2.15, 2.28, and 2.14. The NovemberMarch southern Africa GPCP precipitation anomaly for the two drought summers was over 1.5 standard deviations below the 19792015 mean, while the $1997 / 98$ precipitation anomaly was within 0.25 standard deviations of the mean.
}

TABLE 1. Regression statistics from the regressions of the annual ATLI, AHLI, and ALI on the Niño-3.4 SST index.

\begin{tabular}{lccc}
\hline & ATLI & AHLI & ALI \\
\hline$R^{2}$ & 0.13 & 0.04 & 0.03 \\
$N$ & 37 & 37 & 37 \\
Constant coefficient & 0.48 & 0.45 & 0.54 \\
Constant standard error & 0.04 & 0.03 & 0.03 \\
Constant coefficient $p$ value & $<0.001$ & $<0.001$ & $<0.001$ \\
Niño-3.4 SST coefficient & -0.08 & 0.03 & -0.03 \\
Niño-3.4 SST standard error & 0.04 & 0.03 & 0.03 \\
Niño-3.4 SST $p$ value & 0.029 & 0.265 & 0.299 \\
\hline
\end{tabular}

be more (fewer) tropical low days and fewer (more) heat low days. However, we found that this anticorrelation was in fact very weak, with $R=-0.12$.

Table 1 shows the results of linear regressions of the ATLI, the AHLI, and the ALI onto to the NovemberMarch average Niño-3.4 SST index. The AHLI is not dependent on Niño 3.4 SST $\left(R^{2}=0.01, p=0.27\right)$. The ATLI has an $R^{2}$ coefficient of $0.04(p=0.029)$. However, the regression parameter of the Niño-3.4 SST index switches sign. As a consequence, the ALI does not exhibit a significant dependence on the Niño-3.4 SST index $\left(R^{2}=0.04, p=0.30\right)$. This suggests that considering the Angola heat low and the Angola tropical low as a single feature obscures the relationship between the Angola low and ENSO.

Average GPCP (NOAA 2012) November-March precipitation over southern Africa (south of $15^{\circ} \mathrm{S}$ ) was regressed first against the Niño-3.4 SST index alone, and partial regressions were performed on the residual precipitation against the residual Angola low indices, with regression statistics displayed in Table 2. Regression statistics of precipitation on the ATLI index alone are also shown. Niño-3.4 SST alone was found to explain $52 \%$ of the variance $(p<0.001)$, and the partial regression onto the ATLI explained a further $27 \%$ of the variance $(p=0.001)$. However, the partial regression onto the AHLI did not increase variance explained and was not significant at the 0.05 level. This suggests that it is the Angola tropical low, and not the Angola heat low, which modulates the impact of ENSO on southern Africa precipitation, and that combining the effects of the Angola tropical low and the Angola heat low adds noise to this signal $\left(R^{2}=0.17, p=0.010\right)$.

Figure 8 shows scatterplots of the variables used in the first two regressions described in Table 2, with colors representing the calculated and predicted GPCP precipitation per summer over southern Africa. The colored dots show the GPCP precipitation per summer while the colored lines show the predictions based on the respective regressions. The black line indicates the regression of the ATLI on the Niño-3.4 SST index. 
TABLE 2. Regression statistics for five regressions of November-February southern Africa GPCP precipitation: first column is precipitation regressed onto ENSO; second through fourth columns are partial regressions of the residual of precipitation onto the residuals of ATLI, AHLI and ALI; and fifth column is precipitation regressed onto the ATLI.

\begin{tabular}{|c|c|c|c|c|c|}
\hline & Niño-3.4 only & ATLI and Niño-3.4 & AHLI and Niño-3.4 & ALI and Niño-3.4 & ATLI only \\
\hline$R^{2}$ & 0.52 & 0.27 & 0.00 & 0.17 & 0.36 \\
\hline$N$ & 37 & 37 & 37 & 37 & 37 \\
\hline Variable & ENSO & ATLI & AHLI & ALI & ATLI \\
\hline Partial regression? & No & Yes & Yes & Yes & No \\
\hline Constant coefficient & 17.30 & - & - & - & 14.29 \\
\hline Constant standard error & 0.29 & - & - & - & 0.75 \\
\hline Constant coefficient $p$ value & $<0.001$ & - & - & - & $<0.001$ \\
\hline Variable coefficient & -1.72 & 4.05 & 0.01 & 4.32 & 6.21 \\
\hline Variable standard error & 0.28 & 1.10 & 1.55 & 1.59 & 1.41 \\
\hline Variable $p$ value & $<0.001$ & $<0.001$ & 0.997 & 0.010 & $<0.001$ \\
\hline
\end{tabular}

Adding the ATLI as a variable in the regression (Fig. 8, bottom) explains the variation among the three strongest El Niño events, in contrast to the ENSO-only regression (Fig. 8, top). Furthermore, the difference between the strong La Niña summers starting in 1988, 2007, and 1999 is also explained by the inclusion of the ATLI in the regression. Neither regression predicts the precipitation of 1994 and 2005, which both had strong rainfall anomalies but occurred during the neutral ENSO phase and featured moderate tropical low indices.

These regression results imply that the component of the variation in the Angola low that is independent of ENSO is correlated to the summer mean precipitation across southern Africa. We do not attempt to further examine this correlation here, or make any statements regarding causation or modes of variability. However, we note that future attempts to characterize the modulation of precipitation variability by the Angola low should take the separation of the Angola heat low and the Angola tropical low into account.

\section{Anchoring processes}

Section 3 demonstrated that the climatological Angola low is the combined effect of a series of heat lows and tropical lows. The heat lows tend to form and remain exclusively over the Angola low region. In contrast, tropical lows track across tropical southern Africa, but linger over east Angola. Therefore, tropical lows are more likely to persist in east Angola than elsewhere. If the tropical lows instead tracked away from Angola as quickly as they track toward it, then the climatological depth of the Angola low would be diminished. Thus, the placement of the Angola low in the late summer climatology originates from the behavior of these transient synoptic-scale systems. Throughout the tropics, moist convecting lows are generally transient features and do not usually exhibit the stationary behavior of the tropical lows in the Angola region. This section therefore aims to discover why southern Africa tropical lows behave in this manner.

An analysis of the vorticity budgets of the Angola low phases was carried out in order to explain the motion and structure of the lows. The following equation shows the vorticity budget in the form that has been studied. Here, $\zeta$ is relative vorticity, $\mathbf{v}$ and $\mathbf{v}_{h}$ are the $3 \mathrm{D}$ and $2 \mathrm{D}$ velocities respectively, $\omega$ is vertical velocity in pressure coordinates, and $\mathbf{F}$ is the friction term of the momentum equation. This balance indicates that the possible sources and sinks of vorticity are advection, stretching, twisting, and friction. The friction term cannot be directly computed from resolved model variables, and so is represented by a subgrid-scale residual term.

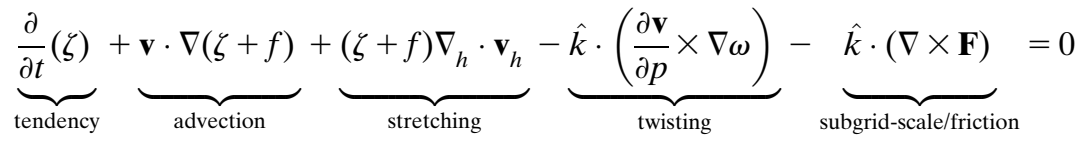

Vertical profiles of the terms of the vorticity budget at the centroids of both heat lows (red) and tropical lows (blue) are shown in Fig. 9. For both phases of the Angola low, the largest source term in the budget is the stretching term, and the largest sink term is friction. This implies vorticity is created by the amplification of cyclonic absolute vorticity in a convergent airmass. Convergence may amplify either relative or planetary 

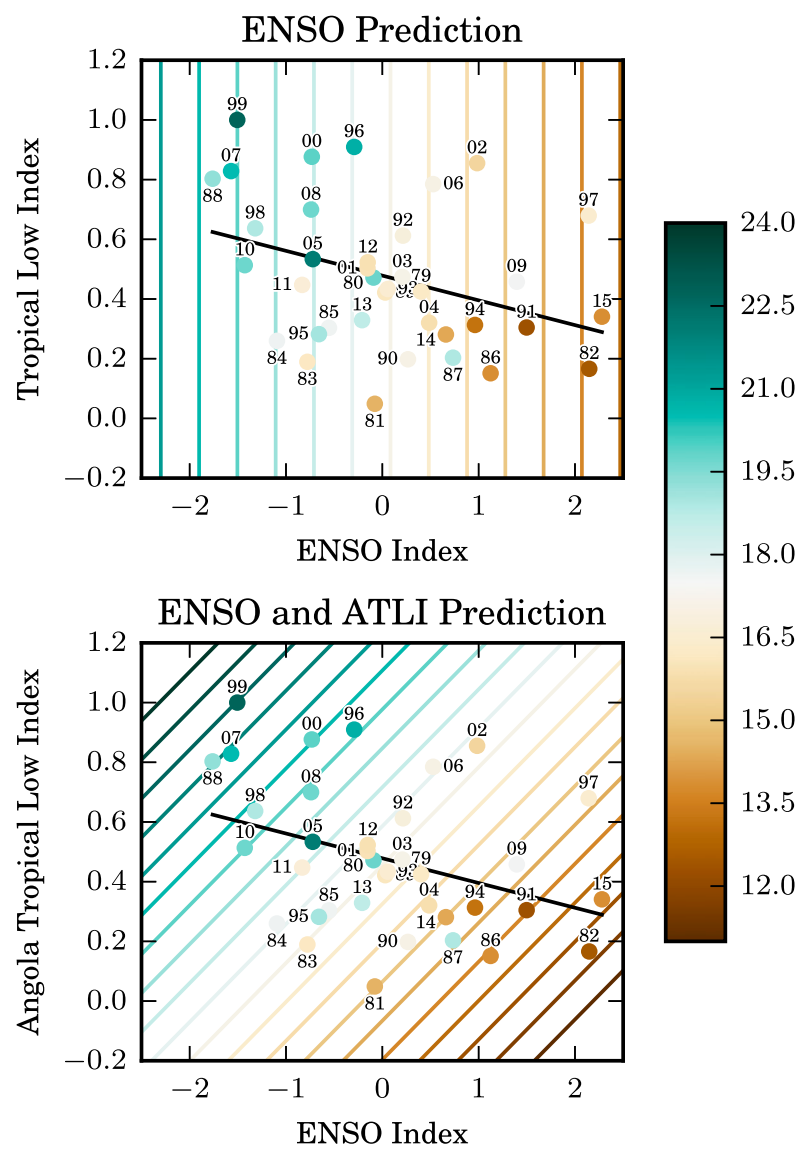

FIG. 8. Scatterplots of November-March Niño-3.4 SST index (K) and ATLI. Point colors represent GPCC precipitation ( $\mathrm{mm}$ per pentad) over African mainland south of $15^{\circ} \mathrm{S}$. Line colors represent precipitation ( $\mathrm{mm}$ per pentad) predicted (top) by the Niño-3.4 SST index only regression (first column of Table 2) and (bottom) the Niño-3.4 SST and ATLI regression (second column of Table 2). The black line shows the predicted ATLI for each value of the Niño-3.4 SST index (first column of Table 1). Labels indicate the year in which each season starts, e.g., 99 for 1999-2000.

vorticity, and may be decomposed into two terms, $\zeta \nabla_{h} \cdot \mathbf{v}_{h}$ and $f \nabla_{h} \cdot \mathbf{v}_{h}$, to reflect this. The majority of this cyclonic acceleration is balanced by an opposing frictional force, but some fraction of it contributes to increasing the cyclonic vorticity of the system.

The dominant role of the stretching term is consistent with the general theory of cyclonic vortices on a rotating plane. A low pressure anomaly is associated with uplift and convergent inflow, which is rotated by the Coriolis force to create cyclonic vorticity. However, a closer analysis of the stretching term indicates that a convergent anabatic sea breeze provides a second-order source of stretching, which may play a role in anchoring tropical lows to the Angola region.

Figure 10 shows the vertical cross section of the anabatic sea breeze as it crosses the coastline at $11^{\circ}-19^{\circ} \mathrm{S}$.
From this it is apparent that the anabatic sea breeze initiates at midday and then advects inland. As it crosses the coastline, the anabatic sea breeze rises up the escarpment and continues its trajectory upward such that its presence is apparent up to $600 \mathrm{hPa}$. As it approaches the coast and proceeds upward, the zonal wind strengthens and hence diverges, causing a plume of divergence ( $\mathrm{col}-$ ored red) rising from the ocean. The direction of the wind ensures that this plume is directed upward and eastward, and rises up over the plateau. The anabatic sea breeze slows down because of friction directly above the land surface, causing horizontal convergence (colored blue). This alternating pattern of divergence and convergence, also reflected in vertical and onshore winds, resembles a topographically generated gravity wave. A second trough of convergence is faintly visible at 1900 local time (LT), centered at around $500 \mathrm{hPa}$. Throughout the course of the night, the gravity wave is advected inland by its own surface winds, and steadily decays. By 0100 LT it is apparent $5^{\circ}$ longitude east of the coastline. The anabatic sea breeze is present in the diurnal climatology every month of the year (not shown), although it is strongest in November when the surface heating is greatest. The surface convergence has the capacity to generate vortex stretching, which can invigorate low pressure systems located in the same region. Meanwhile, the divergence above the boundary layer would generate negative vortex stretching and inhibit the convection.

Figure 11 shows the 6-hourly climatological surface irrotational winds averaged from November to February. The main feature that is apparent is the westerly anabatic sea breeze blowing across the southwest African coastline. The blue colors along the west coast in Fig. 11, left, represent the location of the surface convergence maximum associated with the anabatic sea breeze. The red colors in Fig. 11, right, represent the associated divergence maximum higher in the atmosphere. Both the convergence and divergence zones form bands stretching along the western and southern coastlines, which move inland overnight. By 0100 LT, two regions of strong convergence remain: one at $16^{\circ} \mathrm{S}$, $16^{\circ} \mathrm{E}$ and the other at $24^{\circ} \mathrm{S}, 18.5^{\circ} \mathrm{E}$. Based on Fig. 4 , the former is a preferred location of both Angola heat lows and tropical lows. The latter is coincident with the Kalahari heat low. The divergence zone in Fig. 11 at 1900 LT - directly east of the Angola coast-is completely devoid of heat lows and tropical lows in Fig. 4. This suggests that the surface convergence and midtropospheric divergence of the anabatic sea breeze does indeed influence the placement of the Angola low in the climatological average.

Because the centroids of the Angola lows are variable and the location of the coast is fixed, it is difficult to 

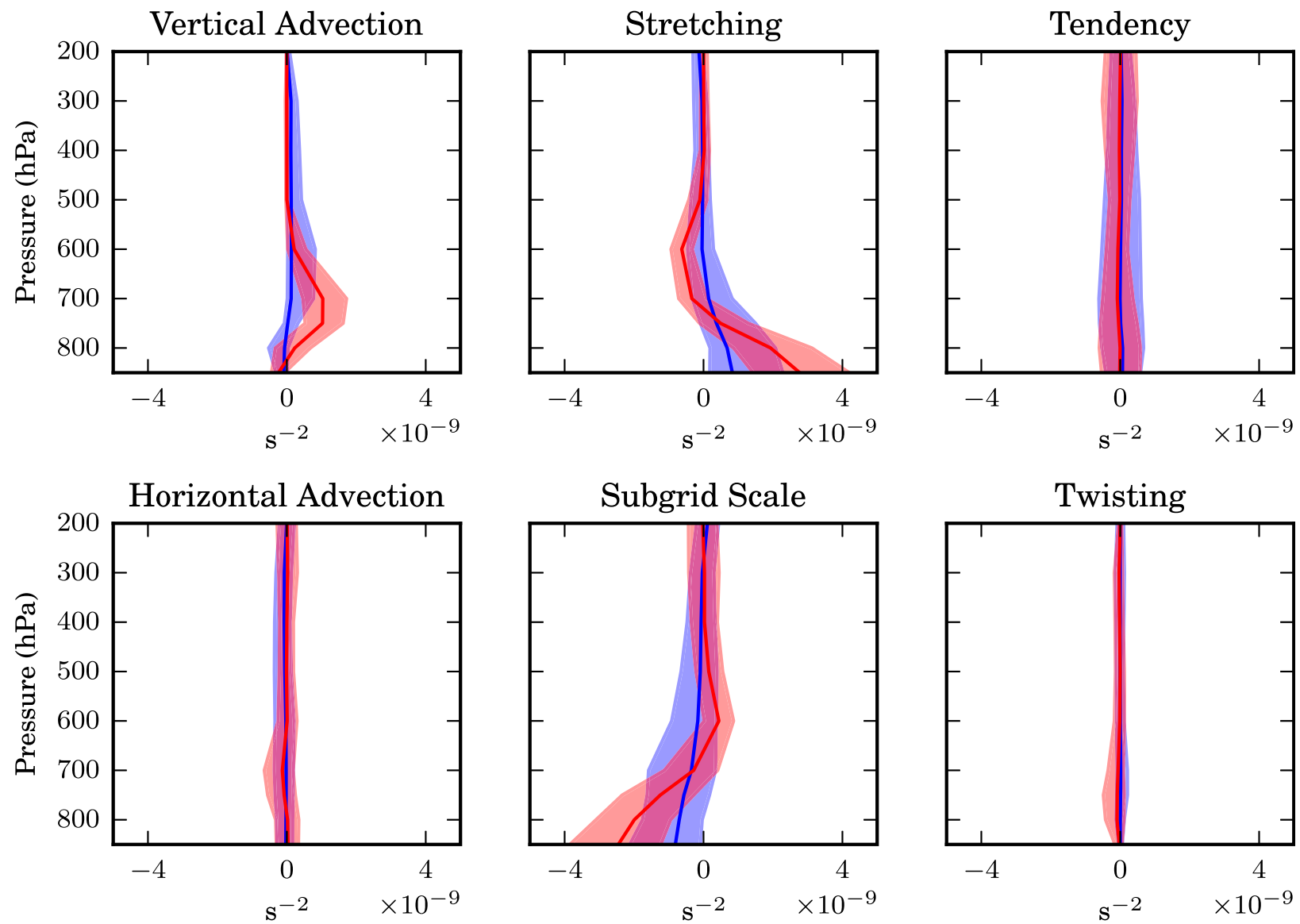

FIG. 9. Vertical profiles of vorticity budget terms during Angola low events (red for heat lows and blue for tropical lows). The solid line indicates the composite mean, and the color-shaded regions represent one standard deviation on either side of the mean. The vorticity budget terms are labeled as per Eq. (1), and the subgrid-scale term represents friction.

compare the stretching due to convergent inflow and the anabatic sea breeze in the same reference frame. We solve this problem by compositing lows centered at a fixed distance from the coast. Figures 12 and 13 show cross sections of longitude against pressure for both stretching terms of the vorticity budget of heat lows and tropical lows respectively at different times of the day. The full vorticity budgets of these composites are shown in the figures in the supplemental material. The first two columns of Figs. 12 and 13 are composited over lows centered $5^{\circ}$ longitude east from the coast, while the lows composited in the second two columns were centered $8^{\circ}$ longitude east from the coast. Because the divergence from the anabatic sea breeze travels approximately $6^{\circ}$ longitude inland (Fig. 11), the anabatic sea breeze may be expected to influence the western set of lows, but not the eastern set. When performing significance testing on these composites, we tested the null hypothesis that each vorticity budget term was equal zero. This means that the alternative hypothesis would imply that a vorticity budget term was a significant source or sink of cyclonic vorticity. This was tested using the Student's $t$ test, with autocorrelation and false discovery rates controlled for as per the other regressions described in section 2 .

To unpack the influence of the anabatic sea breeze on the Angola low, it is useful to consider the influence on the Angola heat low and Angola tropical low separately. As alluded to in section 3b, the anabatic sea breeze is a fundamental component of the Angola heat low. The idealized heat low of Rácz and Smith (1999) featured convergent low-level sea breezes in the afternoon, which were rotated by the Coriolis force into a cyclonic vortex overnight. The sea breezes of Rácz and Smith (1999) originated from all directions. However, on a larger continent and in the presence of easterly trade winds, westerly sea breezes dominated (Spengler and Smith 2008). The sea breeze is a consequence of the mesoscale temperature gradient between the hot land surface and the cold ocean to the west. It is therefore a mechanism through which direct thermal heating may be converted into vorticity. The heating of the easterly trade winds as 

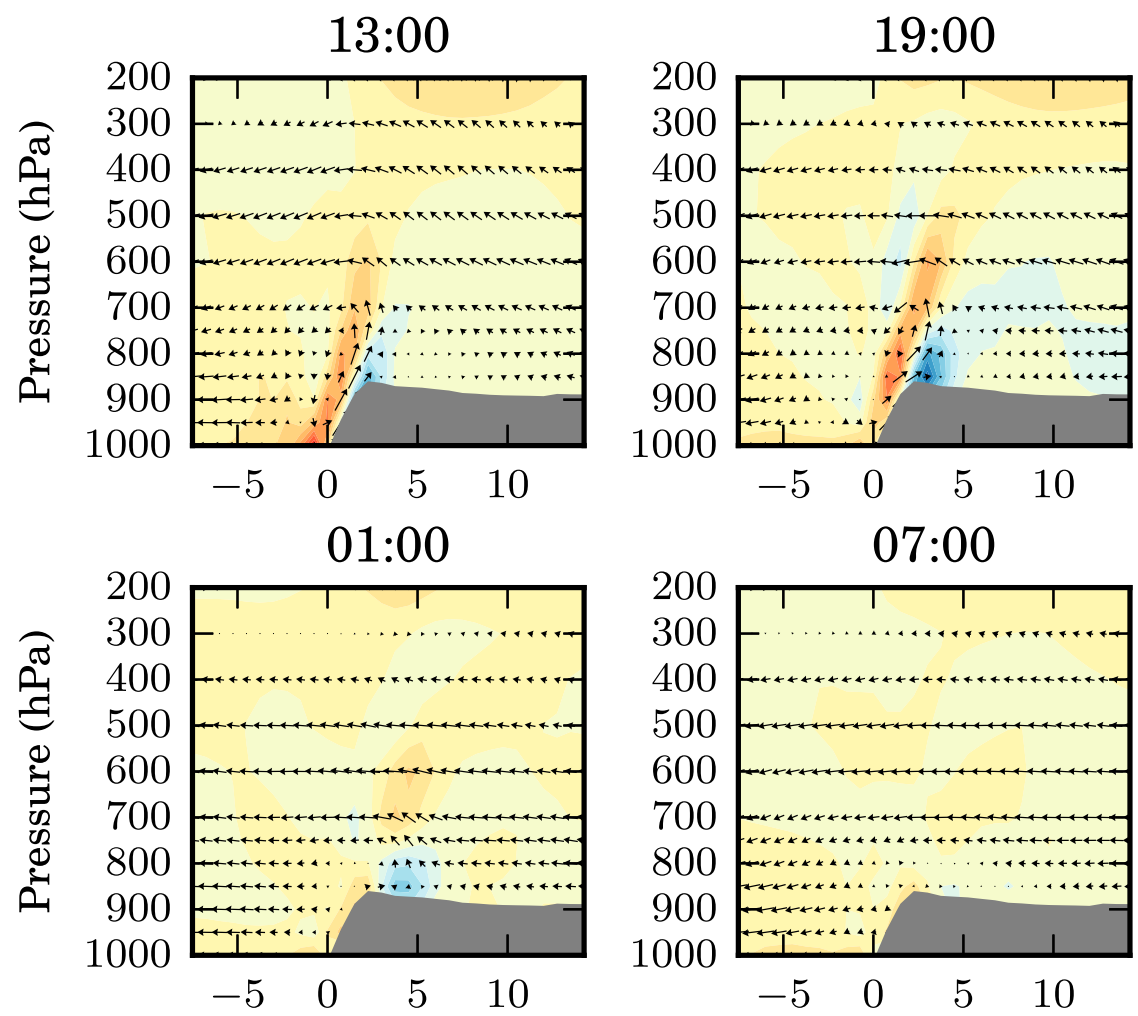

${ }^{\circ} \mathrm{E}$ from Coast

${ }^{\circ} \mathrm{E}$ from Coast

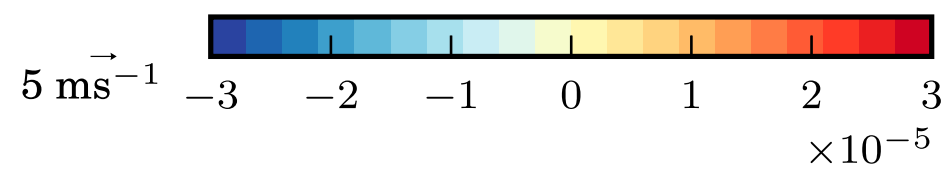

FIG. 10. November-February climatology diurnal winds and horizontal divergence across the Angola coast at $11^{\circ}-19^{\circ} \mathrm{S}$. Vectors show zonal and vertical winds, and red and blue colors show divergence and convergence $\left(s^{-1}\right)$, respectively. The times of the day are (top left) 0100 , (top right) 0700, (bottom left) 1300, and (bottom right) 1900 LT. The $x$ axis is degrees of longitude east of the coastline.

they rise over the plateaus of southern Africa is also expected to play a key role in the formation of the heat lows. However, the sea breeze provides a large component of the convergent inflow that creates cyclonic vorticity through stretching.

In our study, the importance of the sea breeze to the heat lows is apparent in Fig. 12. At 1900 LT, the cyclonic vorticity of the heat low is very small and the primary source of vorticity for lows near the coast in the eastern composite is planetary vorticity stretching associated with the sea breeze. By 0100 LT, this vorticity source has intensified the cyclonic vortex, and relative vorticity stretching has become an important term. By 0700 LT, the cyclonic vortex is still strong but the stretching terms are both greatly reduced, suggesting that the horizontal convergence has dropped (consistent with Fig. 10). At 1300 LT, the vortex and both stretching terms are both weakened once again. Heat lows located farther from the coast in the western composite experience a similar diurnal cycle; however, the initial planetary vorticity stretching originates from a different source. Significantly, $63 \%$ of all heat lows occurred within $5^{\circ}$ of the coast.

The influence that the anabatic sea breeze has on the Angola tropical low is more complicated and requires further investigation. In the eastern composite of Fig. 13, the main source of stretching comes from the relative vorticity convergence at 0100 and $0700 \mathrm{LT}$. The signature of the anabatic sea breeze can be seen in the planetary vorticity stretching term; however, this influence is limited to within $6^{\circ}$ longitude of the coast and does not impact the cores of the tropical lows. In the western composite of Fig. 13, both stretching terms contribute more cyclonic vorticity at the core of the tropical lows. 

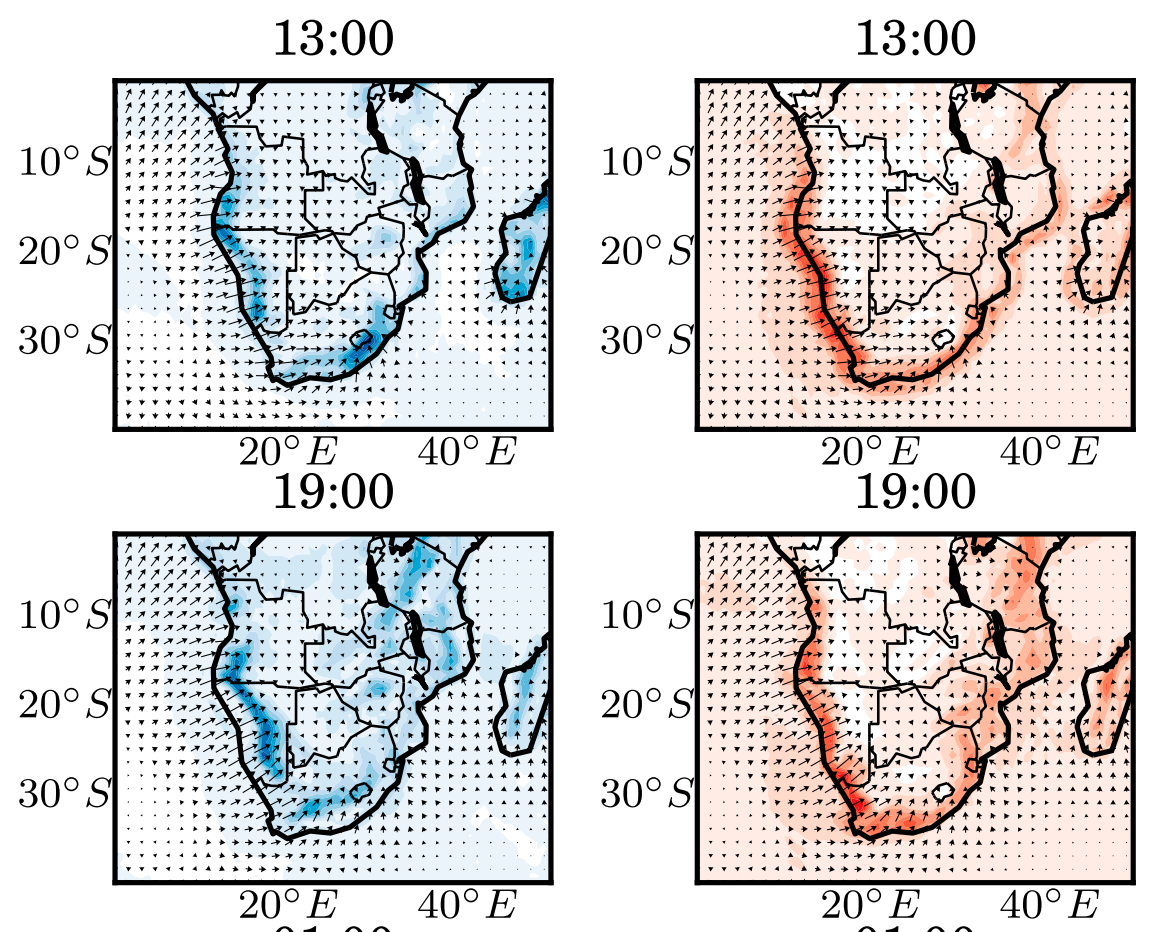

01:00
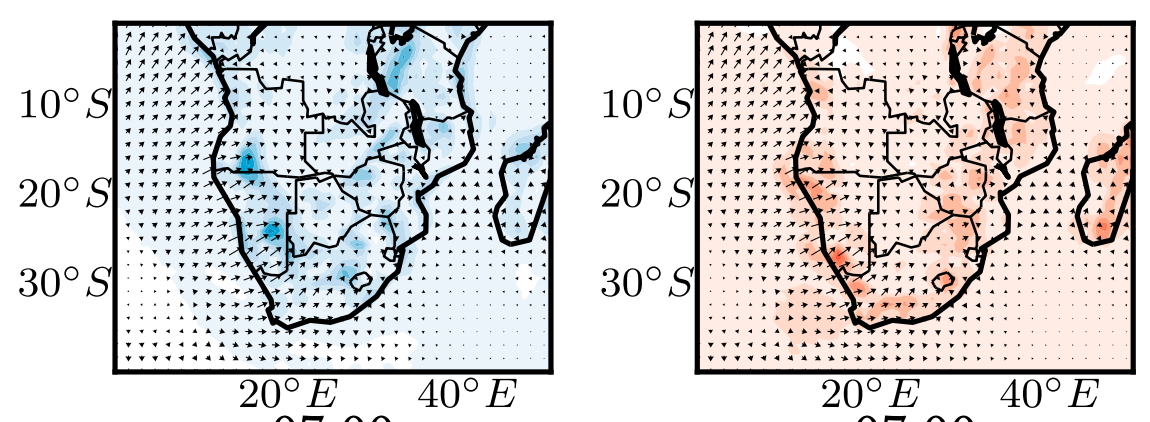

07:00
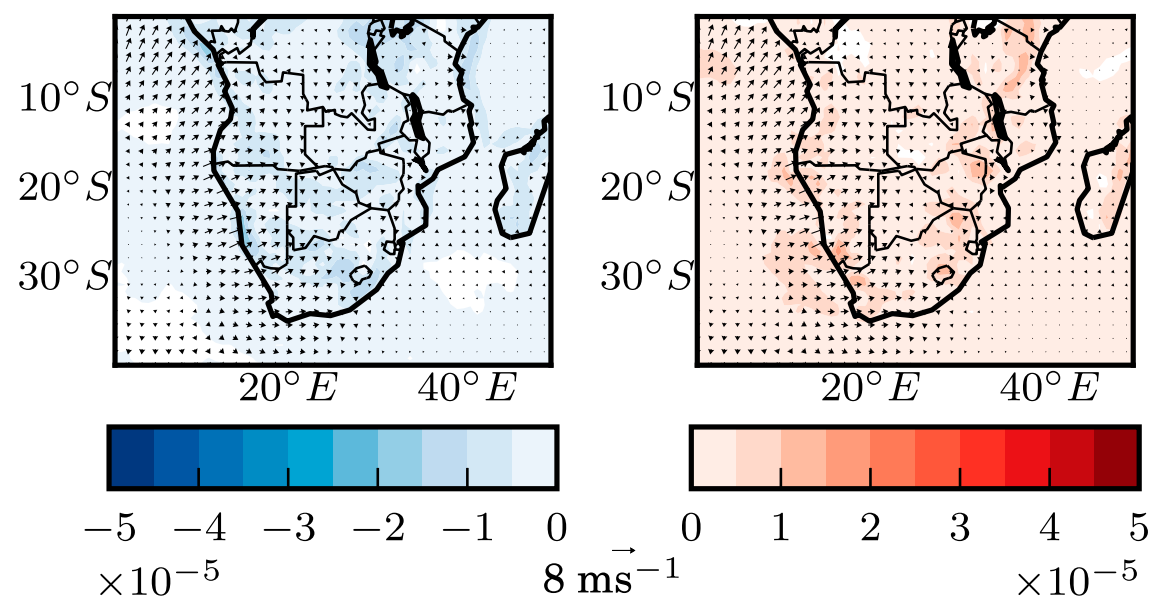

$8 \mathrm{~ms}^{-1}$

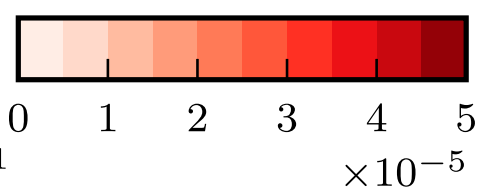

FIG. 11. Irrotational component of diurnal surface winds in the November-February climatology and column maximum (left) convergence and (right) divergence across southern Africa $\left(\mathrm{s}^{-1}\right)$. The times of the day are (top)-(bottom) 1300, 1900, 0100, and 0700 LT. 

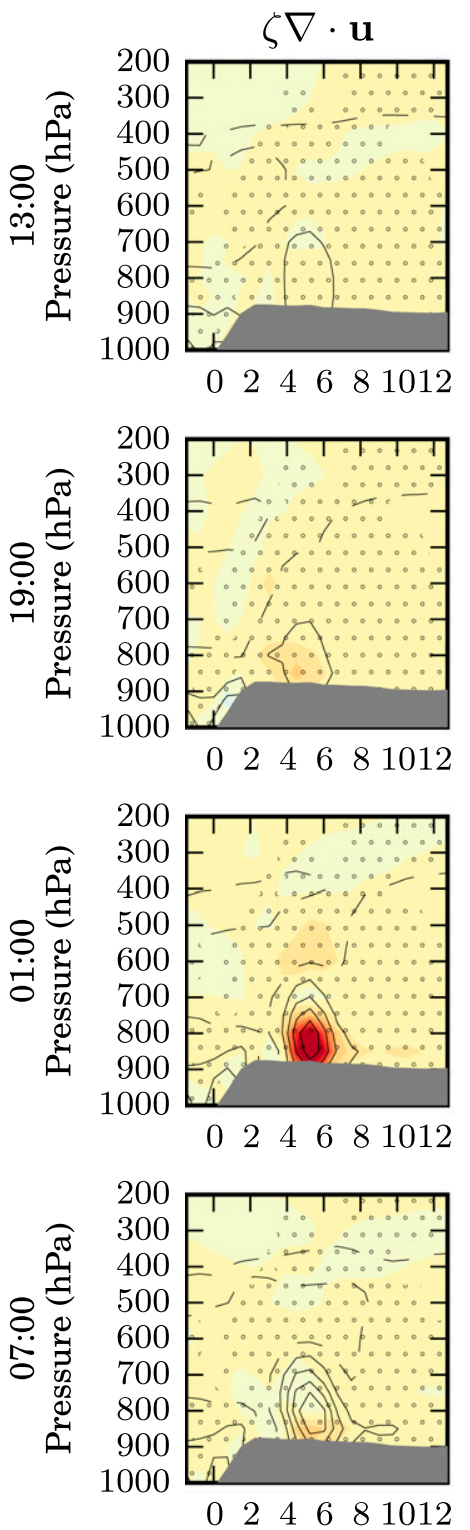

${ }^{\circ} \mathrm{E}$ from Coast
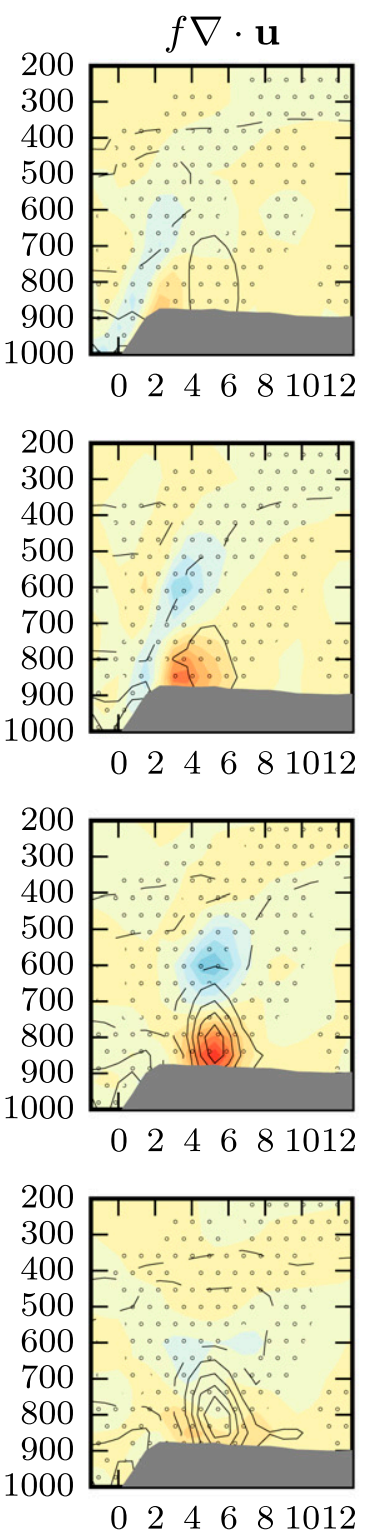

${ }^{\circ} \mathrm{E}$ from Coast

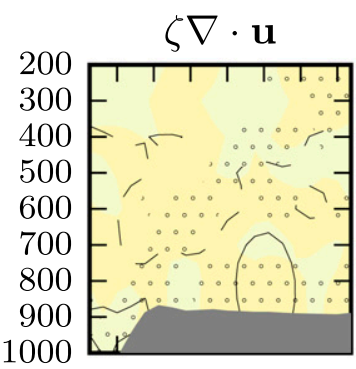

$0 \quad 246681012$

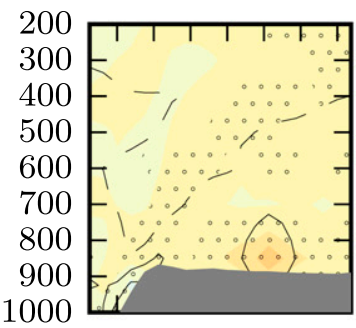

$\begin{array}{llllll}0 & 2 & 4 & 6 & 8 & 1012\end{array}$
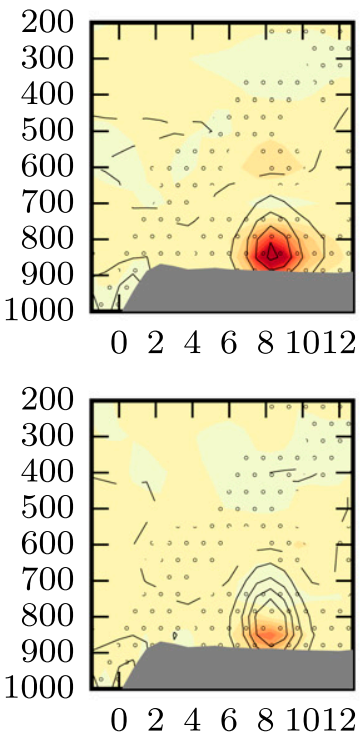

${ }^{\circ} \mathrm{E}$ from Coast

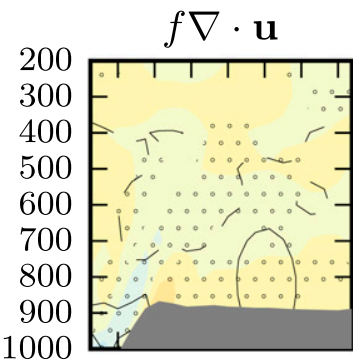

$\begin{array}{llllll}0 & 2 & 4 & 6 & 8 & 1012\end{array}$

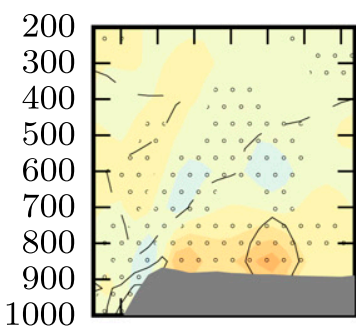

$0 \begin{array}{llllll}0 & 2 & 4 & 6 & 8 & 1012\end{array}$
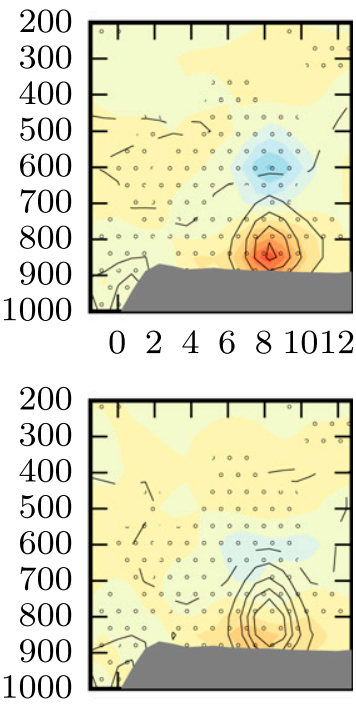

$\begin{array}{llllll}0 & 2 & 4 & 6 & 8 & 1012\end{array}$

${ }^{\circ} \mathrm{E}$ from Coast

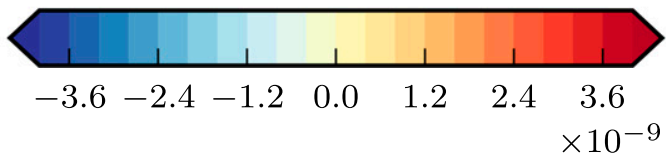

FIG. 12. Vertical cross sections of vorticity budget stretching terms $\left(\mathrm{s}^{-1}\right)$ at (top)-(bottom) 0100, 0700, 1300, and $1700 \mathrm{LT}$. The first and third columns show stretching of relative vorticity, and the second and fourth columns show stretching of planetary vorticity. The first two columns show composites of heat low events located $5^{\circ}$ longitude from the coast, while the second two show heat low events located $8^{\circ}$ longitude from the coast. The cross section is taken across the latitude of the vortex centers. The $x$ axis is degrees longitude east of the coast. Black contours indicate the cyclonic vorticity. (The first contour is $1 \times 10^{-5} \mathrm{~s}^{-1}$, with a $2 \times 10^{-5} \mathrm{~s}^{-1}$ contour interval. Dashed contours indicate anticyclonic vorticity.) Stippling shows the statistically significant grid points, determined based on a threshold $p_{\mathrm{FDR}}^{*}=$ 0.027 . 

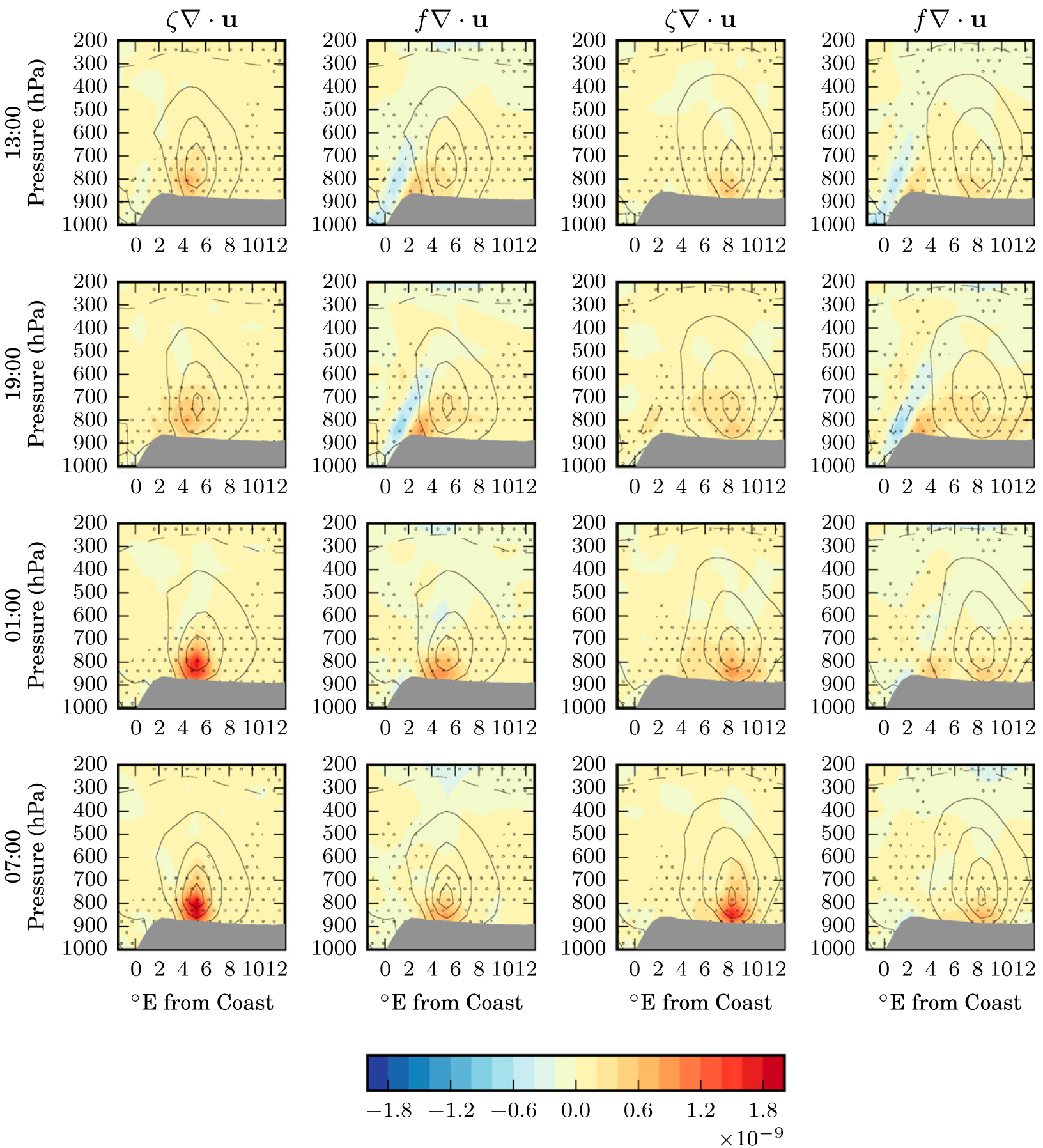

FIG. 13. As in Fig. 12, but for tropical low events. Stippling shows the statistically significant grid points, determined based on a threshold $p_{\mathrm{FDR}}^{*}=0.020$.

Planetary vorticity stretching carries a strong signature of the anabatic sea breeze and contributes to a vorticity source at the cores of the tropical lows about half as strong as that contributed by relative vorticity stretching. Relative vorticity stretching is stronger in the western composite than the eastern composite, which could be due to the anabatic sea breeze influence.
Together, these results imply that vorticity stretching due to the convergence of the anabatic sea breeze can be a second-order vorticity source for tropical lows centered within $6^{\circ}$ longitude of the coast.

The vorticity sink associated with the divergent tail of the anabatic sea breeze is of similar order of magnitude as the vorticity source terms in every case. This 
divergence zone may act as a barrier to eastward propagating tropical lows and prevent them from crossing the coast into the Atlantic Ocean. The full vorticity budget of the western composite (see the figures in the supplemental material) also indicates that low-level cyclonic vorticity is advected inland from the western coast at 1900 LT by the anabatic sea breeze. Therefore, the anabatic sea breeze may cause the tropical lows to linger in the Angola region, as can be observed in Fig. 7 in section 3. This means that the climatology average contains a larger number of days featuring tropical lows. Therefore, the action of the anabatic sea breeze deepens the Angola low and intensifies its cyclonic vorticity in the climatological average.

\section{Discussion and conclusions}

This paper has shown that the Angola low can be separated on a synoptic scale into two distinct phases: the Angola heat low and the Angola tropical low. It was found that this distinction clarifies the link between the Angola low, the precipitation and ENSO on an interannual time scale. The Angola tropical low is stronger during La Niña seasons. However, the relationship between ENSO and the Angola low indices was relatively weak and we found that the Angola low undergoes considerable variability independent of ENSO. A partial linear regression of southern Africa precipitation on the Niño-3.4 SST index and an Angola tropical low index was found to explain the large variance in precipitation during the three strongest El Niño summers in the study period, two of which were associated with severe droughts while a third experienced average rainfall. This regression also did well at explaining the variance between precipitation during the three strongest La Niña summers in the study period.

These regression results suggest that the Angola tropical low is important for southern Africa rainfall. The tropical low events were found to be dynamically similar to monsoon low pressure systems that form throughout the tropical landmasses. However, the key difference between the southern Africa tropical lows and those observed elsewhere was their propensity to linger in the Angola region. This semistationary behavior is fundamental to the impact that the Angola tropical low has on the climatological Angola low. While each transient tropical low spends 2-3 days directly impacting the weather of any given area, a semistationary tropical low may impact the weather for several weeks, building up a stronger influence on the seasonal climate.

Vorticity budget analysis has demonstrated that an anabatic sea breeze circulation plays an important role in anchoring the tropical lows to the Angola region. The impact of the sea breeze on the tropical lows is secondary to the processes that create the tropical lows and only acts as an anchoring mechanism, rather than a formation mechanism. The anabatic sea breeze was shown to be divergent in the midtroposphere near the coast and convergent near the surface and further inland, which enhances the stretching vorticity budget term. This vorticity source strengthens the Angola low inland and weakens it near the coast, inhibiting eastward tracking tropical lows from crossing the coast. An equivalent point of view is that the uplift of the eastern branch of the anabatic sea breeze enhances the convection of the tropical lows, while the subsidence associated with the westward branch of the anabatic sea breeze overturning inhibits convection. This overturning circulation can be clearly seen in Fig. 10 .

By considering the synoptic expression of the Angola low, this paper has revealed the mechanisms that drive it, namely heat lows, tropical lows, and the anabatic sea breeze. This work opens up several avenues of future research. The processes that link the Angola low to southern Africa precipitation, such as tropical-temperate cloud bands and wet spells, should be studied taking into account the two phases of the Angola low. A process-based analysis of the Angola low in CMIP and AMIP models should examine how well the models represent the three mechanisms listed above. These findings will therefore support efforts to reduce uncertainty around future projections of southern Africa precipitation.

Acknowledgments. This work has been generously supported by the Origin Foundation John Monash Scholarship and by the Future Climate for Africa UMFULA project, with financial support from the U.K. Natural Environment Research Council (NERC), NE/M020207/1, and the U.K. Government's Department for International Development (DfID). The data used in this analysis were provided by the European Centre for Medium-Range Weather Forecasts (http://apps.ecmwf.int/datasets/data/interim-full-daily/ levtype $=\mathrm{pl} /$ ), the Physical Science Division of the NOAA/ Earth System Research Laboratory (https://www.esrl.noaa. gov/psd/data/gridded/data.gpcp.html), the NCEP/Climate Prediction Center (https://www.esrl.noaa.gov/psd/data/ gridded/data.ncep.reanalysis2.pressure.html) of the National Oceanic and Atmospheric Administration, and NASA (https://disc.sci.gsfc.nasa.gov/daac-bin/FTPSubset.pl). The authors thank Callum Munday, Neil Hart, and Sebastian Engelstaedter for their inputs, as well as Kerry Cook and two anonymous reviewers for their helpful comments.

\section{REFERENCES}

Berry, G. J., M. J. Reeder, and C. Jakob, 2011: Physical mechanisms regulating summertime rainfall over northwestern Australia. J. Climate, 24, 3705-3717, https://doi.org/10.1175/ 2011JCLI3943.1. 
,-- , and -2012 : Coherent synoptic disturbances in the Australian monsoon.J. Climate, 25, 8409-8421, https://doi.org/ 10.1175/JCLI-D-12-00143.1.

Conway, D., and Coauthors, 2015: Climate and southern Africa's water-energy-food nexus. Nat. Climate Change, 5, 837-846, https://doi.org/10.1038/nclimate2735.

Cook, C., C. J. C. Reason, and B. C. Hewitson, 2004: Wet and dry spells within particularly wet and dry summers in the South African summer rainfall region. Climate Res., 26, 17-31, https://doi.org/10.3354/cr026017.

Cook, K. H., 2000: The South Indian convergence zone and interannual rainfall variability over southern Africa. J. Climate, 13, 3789-3804, https://doi.org/10.1175/1520-0442(2000)013<3789: TSICZA $>2.0 . \mathrm{CO} ; 2$.

Dee, D. P., and Coauthors, 2011: The ERA-Interim reanalysis: Configuration and performance of the data assimilation system. Quart. J. Roy. Meteor. Soc., 137, 553-597, https://doi.org/ 10.1002/qj.828.

ECMWF, 2009: ERA-Interim project. ECMWF public datasets, accessed 30 June 2017, http://apps.ecmwf.int/datasets/data/ interim-full-daily/levtype $=\mathrm{pl} /$.

Godbole, R. V., 1977: The composite structure of the monsoon depression. Tellus, 29, 25-40, https://doi.org/10.3402/ tellusa.v29i1.11327.

Harrison, M. S. J., 1984: A generalized classification of South African summer rain-bearing synoptic systems. J. Climatol., 4, 547-560, https://doi.org/10.1002/joc.3370040510.

Hart, N. C. G., C. J. C. Reason, and N. Fauchereau, 2010: Tropicalextratropical interactions over southern Africa: Three cases of heavy summer season rainfall. Mon. Wea. Rev., 138, 26082623, https://doi.org/10.1175/2010MWR3070.1.

Hunt, K. M. R., A. G. Turner, P. M. Inness, D. E. Parker, and R. C. Levine, 2016: On the structure and dynamics of Indian monsoon depressions. Mon. Wea. Rev., 144, 33913416, https://doi.org/10.1175/MWR-D-15-0138.1.

Hurley, J. V., and W. R. Boos, 2015: A global climatology of monsoon low-pressure systems. Quart. J. Roy. Meteor. Soc., 141, 1049-1064, https://doi.org/10.1002/qj.2447.

James, R., and Coauthors, 2018: Evaluating climate models with an African lens. Bull. Amer. Meteor. Soc., 99, 313-336, https:// doi.org/10.1175/BAMS-D-16-0090.1.

Leslie, L., 1980: Numerical modeling of the summer heat low over Australia. J. Appl. Meteor., 19, 381-387, https://doi.org/ 10.1175/1520-0450(1980)019<0381:NMOTSH>2.0.CO;2.

Lindesay, J. A., 1988: South African rainfall, the Southern Oscillation and a Southern Hemisphere semi-annual cycle. J. Climatol., 8, 17-30, https://doi.org/10.1002/joc.3370080103.

Lyon, B., and S. J. Mason, 2007: The 1997/98 summer rainfall season in southern Africa. Part I: Observations. J. Climate, 20, 5134-5148, https://doi.org/10.1175/JCLI4225.1.

Mudenda, O. S., and Z. L. S. Mumba, 1996: The unusual tropical storm of January 1996. Tech. Rep., Zambia Meteorological Department, 8 pp., http://citeseerx.ist.psu.edu/viewdoc/ download?doi $=10.1 .1 .601 .2986 \&$ rep $=$ rep1\&type $=$ pdf.

Mulenga, H., 1998: Southern African climatic anomalies, summer rainfall and the Angola low. Ph.D. thesis, University of Cape Town, $234 \mathrm{pp}$.

Munday, C., and R. Washington, 2017: Circulation controls on southern African precipitation in coupled models: The role of the Angola low. J. Geophys. Res., 122, 861-877, https://doi.org/ 10.1002/2016JD025736.
NASA, 2016: Modern-Era Retrospective analysis for Research and Applications, version 2. Goddard Earth Sciences Data and Information Services Center, accessed 12 September 2017, https://disc.gsfc.nasa.gov/daac-bin/FTPSubset.pl.

NOAA, 1988: ETOPO5 5-minute gridded elevation data. ETOPO5 download site, accessed 13 January 2017, https:// www.ngdc.noaa.gov/mgg/global/etopo5.HTML.

2012: GPCP Version 2.2 Combined Precipitation Data Set. NOAA/OAR/ESRL PSD, accessed 4 November 2006, https:// www.esrl.noaa.gov/psd/data/gridded/data.gpcp.html.

Rácz, Z., and R. K. Smith, 1999: The dynamics of heat lows. Quart. J. Roy. Meteor. Soc., 125, 225-252, https://doi.org/10.1002/ qj.49712555313.

Reason, C. J. C., 1996: Topography and the dynamical response to easterly flow in Southern Hemisphere subtropical west coast regions. Meteor. Atmos. Phys., 61, 187-199, https://doi.org/ 10.1007/BF01025704.

— usual penetration and impacts over the southern African mainland. Wea. Forecasting, 19, 789-805, https://doi.org/10.1175/ 1520-0434(2004)019<0789:TCEAIU > 2.0.CO;2.

— , and D. Jagadheesha, 2005: A model investigation of recent ENSO impacts over southern Africa. Meteor. Atmos. Phys., 89, 181-205, https://doi.org/10.1007/s00703-005-0128-9.

_ W. A. Landman, and W. Tennant, 2006: Seasonal to decadal prediction of southern African climate and its links with variability of the Atlantic Ocean. Bull. Amer. Meteor. Soc., 87, 941-956, https://doi.org/10.1175/BAMS-87-7-941.

Rouault, M., P. Florenchie, N. Fauchereau, and C. J. C. Reason, 2003: South East tropical Atlantic warm events and southern African rainfall. Geophys. Res. Lett., 30, 8009, https://doi.org/ 10.1029/2002GL014840.

Spengler, T., and R. K. Smith, 2008: The dynamics of heat lows over flat terrain. Quart. J. Roy. Meteor. Soc., 134, 2157-2172, https:// doi.org/10.1002/qj.342.

—, M. J. Reeder, and R. K. Smith, 2005: The dynamics of heat lows in simple background flows. Quart. J. Roy. Meteor. Soc., 131, 3147-3165, https://doi.org/10.1256/ qj.04.177.

Taljaard, J. J., 1953: The mean circulation in the lower troposphere over southern Africa. S. Afr. Geogr. J., 35, 33-45, https://doi.org/10.1080/03736245.1953.10559299.

1972: Synoptic meteorology of the Southern Hemisphere. Meteorology of the Southern Hemisphere, Meteor. Monogr., No. 35, Amer. Meteor. Soc., 139-213.

Todd, M. C., and R. Washington, 1999: Circulation anomalies associated with tropical-temperate troughs in southern Africa and the southwest Indian Ocean. Climate Dyn., 15, 937-951, https://doi.org/10.1007/s003820050323.

Vizy, E. K., and K. H. Cook, 2016: Understanding long-term (19822013) multi-decadal change in the equatorial and subtropical South Atlantic climate. Climate Dyn., 46, 2087-2113, https:// doi.org/10.1007/s00382-015-2691-1.

- — - J. Chimphamba, and B. McCusker, 2015: Projected changes in Malawi's growing season. Climate Dyn., 45, 16731698, https://doi.org/10.1007/s00382-014-2424-x.

Wilks, D. S., 2011: Statistical Methods in the Atmospheric Sciences. 3rd ed. Academic Press, 676 pp.

Zunckel, M., Y. Hong, K. Brassel, and S. O’Beirne, 1996: Characteristics of the nocturnal boundary layer: Okaukuejo, Namibia, during SAFARI-92. J. Geophys. Res., 101, 23757-23 766, https://doi.org/10.1029/95JD00624. 
